\title{
Using Tropopause Maps to Diagnose Midlatitude Weather Systems
}

\author{
Michael C. Morgan \\ Department of Atmospheric and Oceanic Sciences, University of Wisconsin-Madison, Madison, Wisconsin \\ JOHN W. NIELSEN-GAMMON \\ Department of Meteorology, Texas A\&M University, College Station, Texas
}

(Manuscript received 23 June 1997, in final form 28 November 1997)

\begin{abstract}
The use of potential vorticity (PV) allows the efficient description of the dynamics of nearly balanced atmospheric flow phenomena, but the distribution of PV must be simply represented for ease in interpretation. Representations of PV on isentropic or isobaric surfaces can be cumbersome, as analyses of several surfaces spanning the troposphere must be constructed to fully apprehend the complete PV distribution.

Following a brief review of the relationship between PV and nearly balanced flows, it is demonstrated that the tropospheric PV has a simple distribution, and as a consequence, an analysis of potential temperature along the dynamic tropopause (here defined as a surface of constant PV) allows for a simple representation of the upper-tropospheric and lower-stratospheric PV. The construction and interpretation of these tropopause maps, which may be termed "isertelic" analyses of potential temperature, are described. In addition, techniques to construct dynamical representations of the lower-tropospheric PV and near-surface potential temperature, which complement these isertelic analyses, are also suggested. Case studies are presented to illustrate the utility of these techniques in diagnosing phenomena such as cyclogenesis, tropopause folds, the formation of an upper trough, and the effects of latent heat release on the upper and lower troposphere.
\end{abstract}

\section{Introduction}

For potential vorticity (PV) to be qualitatively applied in describing the evolution of tropospheric synopticscale flows, the three-dimensional PV and surface potential temperature distributions must be simply represented and easily interpreted. Toward this goal, Hoskins et al. (1985, HMR hereafter) have advocated the construction of isentropic PV analyses and surface potential temperature maps to describe and represent dynamical processes within the atmosphere. By plotting Ertel PV on an isentropic surface, one has the advantage of viewing the dynamics of a conserved variable along the surface of another conserved variable. Thus, with the wind field superposed on an isentropic analysis of PV, one may deduce the conservative (advective) time tendency of the PV. A distinct disadvantage of this technique is that several isentropic surfaces must be viewed in order to apprehend the full three-dimensional distribution of PV and PV advection. Alternatively, the mean PV within all layers intersecting the tropopause, or VIP (vertically integrated potential vorticity), may be plotted

Corresponding author address: Prof. Michael C. Morgan, Department of Atmospheric Sciences, University of Wisconsin-Madison, 1225 West Dayton St., Madison, WI 53706.
(Shapiro and Grell 1994), but the evolution of VIP is not governed by a single two-dimensional wind field.

Bleck (1990) proposed the three-dimensional depiction of an isosurface of isentropic vorticity (the vertical component of absolute vorticity computed from winds along an isentropic surface). Bleck's technique has the advantage of combining upper- and lower-tropospheric information onto a single map, but with a resulting loss of precision as to the locations and amplitudes of various features. Also, unlike PV, isentropic vorticity is not conserved following adiabatic, frictionless flow, so that the evolution of the isentropic vorticity field is difficult to infer from an instantaneous depiction. Alternatively, three-dimensional isosurfaces of Ertel PV have been utilized by several authors (including Uccellini 1990; Lamarque and Hess 1994; Rotunno et al. 1994) to depict the structure of the tropopause during tropopause fold events. This provides a clear depiction of the distribution of PV, but like Bleck's method, it is difficult to incorporate wind information to infer the evolution.

The focus of this paper is the analysis of both potential temperature and wind along a two-dimensional projection of the dynamic tropopause (defined as a surface of constant Ertel PV). This analysis (here referred to as a tropopause map) exploits the rather simple distribution of tropospheric PV: as will be demonstrated in the next section, isentropic gradients of PV are con- 
centrated at the tropopause. Tropopause maps are a compact way to represent this distribution. Thus, the essential character of the upper-tropospheric PV may be depicted on a single chart, rather than several isentropic maps.

Tropopause maps, often in conjunction with analyses of lower-tropospheric potential temperature, have been used by many authors in studies of surface cyclogenesis (e.g., Hoskins and Berrisford 1988; Davis and Emanuel 1991; Hakim et al. 1995; Bosart et al. 1996; Bresky and Colucci 1996). Thorncroft et al. (1993) used the analyses to compactly represent the evolution of upper-tropospheric PV in a modeling study of life cycles of baroclinic waves. Upper-level systems examined using tropopause maps include a tropopause fold (Nielsen et al. 1991), a blocking anticyclone (Morgan et al. 1991), a cutoff cyclone (Bell and Bosart 1993), and mobile troughs (Nielsen-Gammon 1995; Lackmann et al. 1997). $\mathrm{Wu}$ and Emanuel (1993) and Bosart and Lackmann (1995) used the analyses to represent the outflow from tropical cyclones and the interaction of tropical cyclones with midlatitude systems.

Despite the growing use of such analyses, no comprehensive discussion of the motivation for these analyses, nor a guide to constructing or interpreting them, has been presented. The intent of this paper is to present various techniques for representing the dynamically important characteristics of the tropospheric PV distribution in a compact form and to offer an interpretation for these representations. The paper is divided into six sections, any of which may be skipped without serious loss of continuity. In section 2 , the theoretical and observational motivation for tropopause maps is presented. Section 3 describes and contrasts the various techniques one might use to represent the PV near the tropopause and the potential temperature and PV distribution in the lower troposphere. The next two sections are brief case studies of cyclogenesis that illustrate how tropopause maps may be used to diagnose and interpret synopticscale (i.e., quasi-balanced) weather systems. A summary and further suggestions for how these analyses might be utilized is presented in section 6 .

\section{Observational and dynamical motivation}

\section{a. Balanced flow, $P V$, and $P V$ inversion}

A characteristic of low Rossby number flow in rotating fluids is the tendency of the flow toward balance. A general type of balance, which subsumes geostrophic balance and includes the effects of streamline curvature, is nonlinear balance (also referred to as Charney balance) (Charney 1955). Nonlinear balance approaches geostrophic balance as the Rossby number becomes small and is exactly gradient wind balance for axisymmetric flow.

A "balance system" includes a balance equation (a truncated form of the divergence equation, which in general relates the streamfunction, $\psi$, to the geopoten- tial, $\varphi$ ), a similarly truncated form of the vorticity equation, a thermodynamic equation, and a mass conservation equation. The initial conditions in a time integration of a balance system need only be specified by a single variable (Gent and McWilliams 1983). A familiar example is a flow satisfying the quasigeostrophic system. As long as $\zeta / f_{0}>-1$ (where $\zeta$ is the relative vorticity and $f_{0}$ is a characteristic midlatitude value of the Coriolis parameter), all fields (wind, temperature, vertical motion, and height tendency) may be expressed in terms of the instantaneous geopotential height field. All fields could also, in principle, be specified in terms of the instantaneous temperature field, or even a single component of the wind field.

The PV can also be used for this purpose. In their review, HMR discussed the principles of conservation and invertibility of PV. The invertibility principle states that the three-dimensional distribution of PV within some domain and boundary conditions on that domain uniquely determine the velocity and temperature distribution consistent with a particular balance constraint. The conservation principle states that for inviscid flows in which the gradient of diabatic heating does not project onto the local absolute vorticity vector, PV is conserved following the fluid motion. Together, conservation and invertibility imply that the dynamics of quasi-balanced flows may be expressed simply and entirely in terms of the distribution of $P V$ and the boundary conditions necessary in the inversion ${ }^{1}$ of the $P V$. The use of conservation and invertibility to infer the dynamics of quasibalanced flows is called "PV thinking."

A simple example of conservation and invertibility is nondivergent barotropic flow. For such a flow, the absolute vorticity and lateral boundary conditions contain all of the dynamical information concerning the fluid motion. The streamfunction field, which can be determined from the relative vorticity field through the inversion of a two-dimensional elliptic operator, completely specifies the velocity field. The balance condition that this flow satisfies is nonlinear balance.

In the quasigeostrophic (QG) system, the quasigeostrophic potential vorticity (hereafter QGPV, also known as the pseudo-PV) is conserved following the geostrophic flow (Charney and Stern 1962). Quasigeostrophic $\mathrm{PV}, q_{p}$, is defined as

$$
q_{p}-f \equiv \frac{1}{f_{0}} \nabla^{2} \varphi^{\prime}+f_{0} \frac{\partial}{\partial p}\left(\frac{1}{S} \frac{\partial}{\partial p} \varphi^{\prime}\right),
$$

where $f$ is the Coriolis parameter, $S$ is a reference state static stability parameter, and $p$ is pressure. As with nondivergent barotropic flow, the definition of PV is also a statement of the invertibility principle: the QGPV

\footnotetext{
1 "Inversion" in this context is the mathematical process of calculating the wind and temperature distribution from the PV distribution.
} 
is related to the perturbation ${ }^{2}$ geopotential, $\varphi^{\prime}$ [and the perturbation streamfunction $\left(\psi^{\prime}=\varphi^{\prime} / f_{0}\right)$, which is geostrophic] through a three-dimensional elliptic operator. Because the operator is linear, its inversion is fairly straightforward to perform. Applications of the inversions of QGPV to determine balanced height perturbations using observed atmospheric data include Robinson (1988), Holopainen and Kaurola (1991), Black and Dole (1993), Hakim et al. (1996), and NielsenGammon and Lefevre (1996).

A more general form of PV that has also been used in observational studies is Ertel $\mathrm{PV}, Q$, which with the hydrostatic approximation is

$$
Q=g \frac{\zeta_{a \theta}}{\sigma}
$$

In this expression, $g$ represents the gravitational acceleration, $\zeta_{a \theta}$ the component of absolute vorticity normal to an isentropic surface, and $\sigma=-\partial p / \partial \theta$ is the pseudodensity, inversely proportional to the static stability. Ertel PV is conserved by the full (three-dimensional) adiabatic, inviscid, balanced, or unbalanced flow.

While an exact inversion statement does not exist for Ertel PV, Davis and Emanuel (1991) found a method of inversion for an approximate form of $Q$ in which $\zeta_{a \theta}$ in (2.2) is replaced by the isentropic vorticity of the nondivergent wind. Studies of surface cyclogenesis using nonlinear balance inversion include Davis and Emanuel (1991), Davis (1992b), Davis et al. (1993), Davis et al. (1996), and Bresky and Colucci (1996). Wu and Emanuel (1995a,b) have applied the technique to studying the motion of hurricanes.

With any form of balanced, quasi-horizontal flow, local extrema of the PV field tend, through invertibility, to be associated with local extrema of the streamfunction field. Potential vorticity extrema of the same sign as the local Coriolis parameter are associated with cyclonic circulations, while extrema of opposite sign are associated with anticyclonic circulations. ${ }^{3}$ Complex distributions of PV may [to the extent that the definition of $\mathrm{PV}$ is linear with respect to the streamfunction; see Davis (1992a) or Thorpe and Bishop (1995) for a discussion of this issue] be interpreted as a set of individual PV anomalies and their individual associated circulations added together to obtain the total flow field. Surface potential temperature variations are related to streamfunction variations in a similar fashion. As shown by Bretherton (1966) for quasigeostrophy and Thorpe (1986) for gradient wind balance, locally high (low)

\footnotetext{
${ }^{2}$ Perturbation refers to a deviation from a reference state.

${ }^{3}$ The circulations are not limited to the level of the PV extrema but rather extend through a depth of the troposphere proportional to the horizontal length scale of the extrema, and inversely proportional to the reference state stratification.
}

values of surface potential temperature are associated with local cyclonic (anticyclonic) circulations. ${ }^{4}$

With a balance system the divergent flow and tendencies of both streamfunction and geopotential may be diagnosed from the evolution of PV. The QG height tendency equation is nothing more than the time derivative of (2.1). Case studies of surface or upper-tropospheric cyclogenesis in which balanced height tendencies associated with QGPV advections have been diagnosed include Hakim et al. (1996) and Nielsen-Gammon and Lefevre (1996). The situation is somewhat more complicated with nonlinear balance because $Q$ is advected by the full three-dimensional wind field, so an omega equation must be solved jointly with the tendency equations (Davis and Emanuel 1991; Davis et al. 1996).

\section{b. The observed structure of tropospheric and lower-stratospheric $P V$}

In most of the studies discussed above, the variations of PV near the tropopause, or, equivalently, the variations in the position of the tropopause, were critical elements of the evolving synoptic-scale weather systems. The stratosphere possesses higher values of thermal stratification and PV than the troposphere, as well as relatively higher concentrations of certain chemical species such as ozone. Depending on one's purpose, a representative transitional value of any of these quantities may be used to identify the tropopause. For application to radiosonde observations, the World Meteorological Organization (WMO) defines the tropopause as the lower boundary of a layer in which the lapse rate is less than $2^{\circ} \mathrm{C} \mathrm{km}^{-1}$ for at least $2 \mathrm{~km}$ (WMO 1992). Because the stretching or shrinking of air columns can lead to discontinuous changes in the location of the lapse-rate-defined tropopause without causing any mixing between the troposphere or stratosphere or any change in the chemical composition of the affected layer, studies of troposphere-stratosphere exchange frequently define the tropopause as a particular value of PV (e.g., Staley 1962; Danielsen 1968; Shapiro 1980; Danielsen and Hipskind 1980). This PV-defined tropopause, called a "dynamic tropopause" by Danielsen and Hipskind and others, is much more spatially and temporally continuous than a lapse-rate-defined tropopause.

As discussed by Hoerling et al. (1991) (see also Spaete et al. 1994), a variety of PV values have been used to define the tropopause, ranging from 1 to 3.5 PVU (1 $\mathrm{PV}$ unit $=10^{-6} \mathrm{~m}^{2} \mathrm{~s}^{-1} \mathrm{~K} \mathrm{~kg}^{-1}$; HMR). In a typical cross section (such as Fig. 1a), the 1-3 PVU band tends to lie within the transition zone between the weak stratification of the upper troposphere and the relatively

\footnotetext{
${ }^{4}$ Due to the geometry of the situation, there are some differences in the dynamical behavior and evolution of surface anomalies; see Held et al. (1995) for a comprehensive discussion.
} 

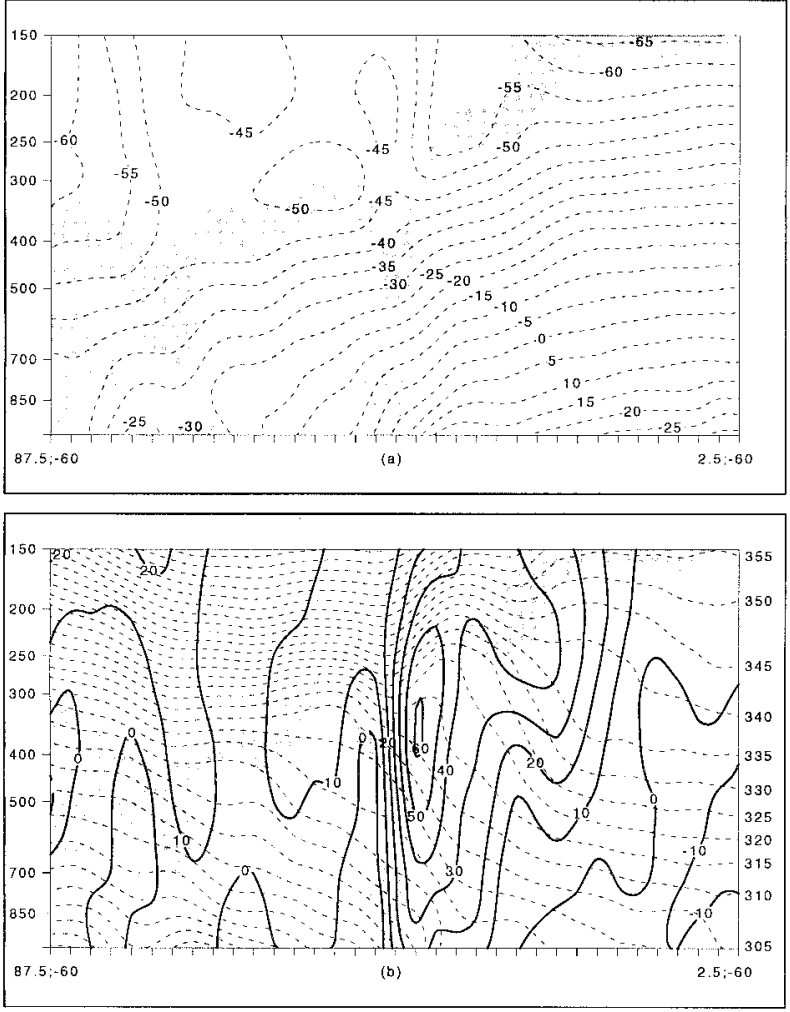

FIG. 1. (a) Cross section of temperature (dashed, contour interval $5^{\circ} \mathrm{C}$ ) and PV (shaded, values between 1 and $3 \mathrm{PVU}$ ) along $60^{\circ} \mathrm{W}$ from $2.5^{\circ} \mathrm{N}$ to $87.5^{\circ} \mathrm{N}$ at 0000 UTC 12 March 1993. (b) Cross section of potential temperature (dashed, contour interval $5 \mathrm{~K}$ ), PV (shaded, values between 1 and $3 \mathrm{PVU}$ ), and isotachs of the zonal component of the wind (solid, contour interval $10 \mathrm{~m} \mathrm{~s}^{-1}$ ) along $60^{\circ} \mathrm{W}$ from $2.5^{\circ} \mathrm{N}$ to $87.5^{\circ} \mathrm{N}$ at $0000 \mathrm{UTC} 12$ March 1993

strongly stratified, nearly isothermal lower stratosphere. The much lower tropopause near the pole relative to near the equator is typical. Near jet streams (Fig. 1b), the 1-3 PVU band is strongly sloped. This tendency for the tropopause to become nearly vertical within upperlevel jet streams is well established (e.g., Platzman 1949; Defant and Taba 1957; Palmén and Newton 1969; Shapiro et al. 1987; Morgan 1994). The polar jet, near the center of the cross section, is located above a region of enhanced middle and lower-tropospheric baroclinicity (the "polar front"), whereas the subtropical jet, above and to the south of the polar jet in Fig. 1b, is associated with a region of shallower baroclinicity, with temperature gradients confined to the middle and upper troposphere. Shapiro and Keyser (1990) note that zonally or seasonally averaged meridional cross sections would contain only a broad sloping tropopause associated with the subtropical jet due to the spatial variability of the polar jet.

The near-vertical tropopause within upper-level jets implies that large horizontal gradients of PV should coincide with upper-level wind maxima at tropopause level. As an example, the 250-hPa surface (Fig. 2a) is typically beneath the tropopause in the Tropics and subtropics, whereas it is above the tropopause in high latitudes. The intersection of the tropopause with the 250$\mathrm{hPa}$ surface may be found meandering across the map between $25^{\circ} \mathrm{N}$ and $65^{\circ} \mathrm{N}$, separating the high, near-uniform stratospheric values of $\mathrm{PV}$ in high latitudes from the low, near-uniform tropospheric values of PV in the Tropics and subtropics. In the vicinity of the tropopause there is a tendency for the wind vectors to be nearly aligned with the isopleths of $Q$. Stronger winds generally coincide with the larger magnitudes in the lateral gradients of PV near the tropopause. The close correspondence between localized regions of relatively high (low) PV and cyclonic (anticyclonic) circulations, discussed in section 1, may also be seen. Of particular importance to what follows is that, in general, features in the wind field are defined more by bends in the strong PV gradient of the tropopause than by individual PV extrema.

Similar distributions of PV and winds are found on the $310 \mathrm{~K}$ and $350 \mathrm{~K}$ isentropic surfaces (Figs. $2 \mathrm{~b}$ and 2c). The tendency for the wind vectors to be nearly aligned with the isopleths of $Q$ is again fairly evident. On the $310 \mathrm{~K}$ surface, north of about $35^{\circ} \mathrm{N}$, the maximum winds are associated with the polar jet stream, while on the $350 \mathrm{~K}$ surface, wind speed is maximized in the subtropical jet to the south of $35^{\circ} \mathrm{N}$. The opposing slopes of the PV and potential temperature surfaces (as seen in Fig. 1b) results in the PV gradients along isentropic surfaces being sharper than gradients along isobaric surfaces. The magnitude of the PV gradient is strongest near the tropopause. Again, meanders of the 1-3 PVU gradient correspond to troughs and ridges, and we note that the position of this gradient could reliably be represented by any contour between 1.5 and 3 PVU.

Such concentrated PV gradients, while common, do not appear in climatological cross sections. Climatological PV distributions are inevitably smooth because the averaging is performed across a spectrum of polar and subtropical jet positions. However, Rossby waves in the upper troposphere interact with the more concentrated instantaneous PV distribution of their environment, rather than the smoother climatological distribution.

To illustrate the characteristic structure of the PV gradient along the tropopause, a "Lagrangian average" of the meridional isentropic PV gradient relative to the position of the dynamic tropopause has been constructed using twice-daily National Meteorological Center (NMC, now known as the National Centers for Environmental Prediction) Northern Hemisphere analyses interpolated to isentropic surfaces. For the month of January 1991, at each synoptic time, the location of the 1.5 PVU contour was determined for each longitude. The meridional potential vorticity gradient was calculated and tabulated at this location and at fixed distances north and south, and then zonally and time averaged. The result of this calculation for the $320 \mathrm{~K}$ surface is shown in Fig. 3. 

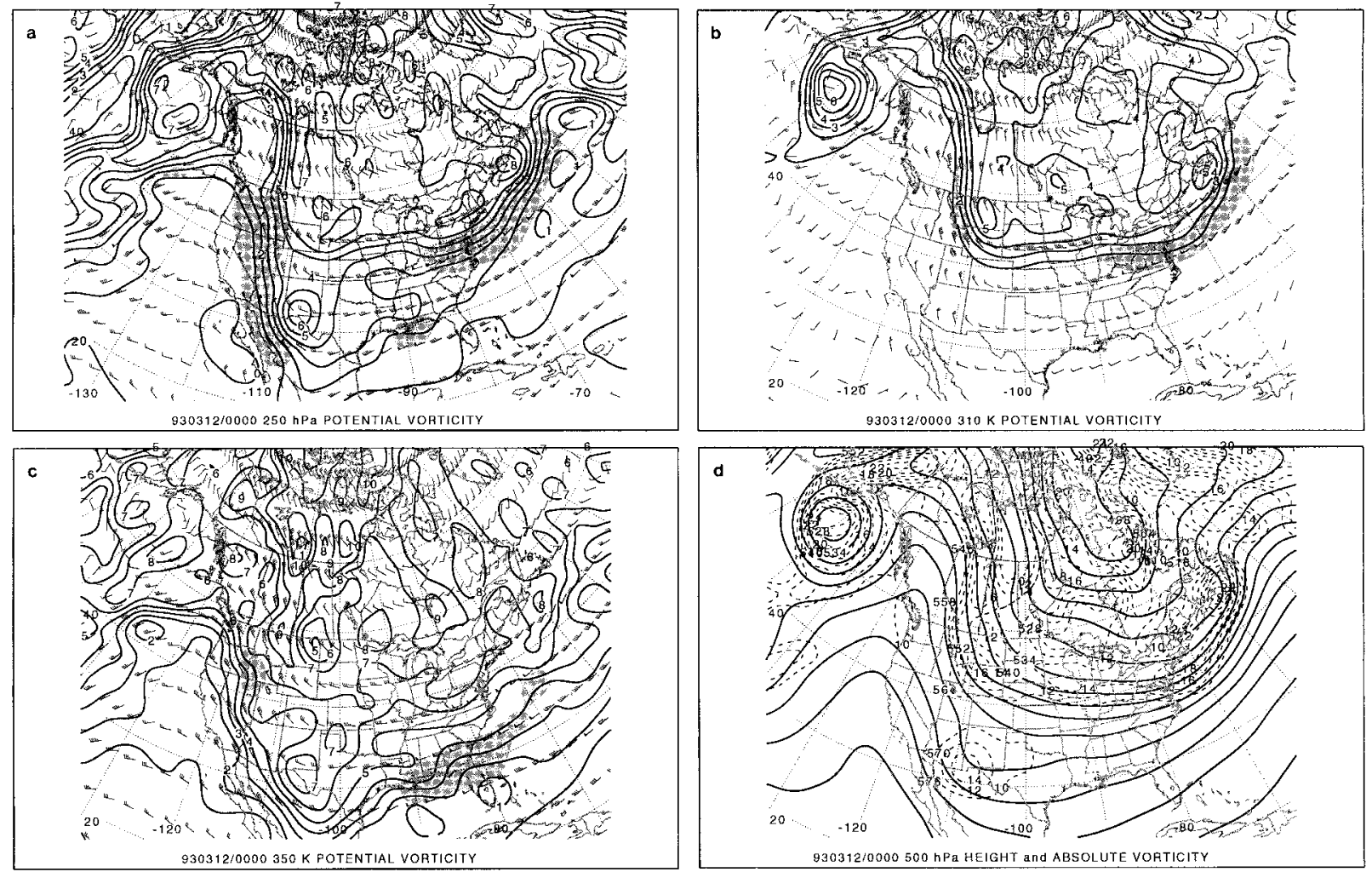

FIG. 2. Ertel PV (solid, contour interval 1 PVU), wind (short barb $=5 \mathrm{~m} \mathrm{~s}^{-1}$; long barb $=10 \mathrm{~m} \mathrm{~s}^{-1}$; pennant $=50 \mathrm{~m} \mathrm{~s}^{-1}$ ), and wind speed (shaded: below $35 \mathrm{~m} \mathrm{~s}^{-1}$ unshaded, shade interval $15 \mathrm{~m} \mathrm{~s}^{-1}$ ) on the (a) 250 -hPa surface, (b) $310 \mathrm{~K}$ isentropic surface, (c) $350 \mathrm{~K}$ isentropic surface, and (d) 500-hPa geopotential height (solid, contour interval $6 \mathrm{dam}$ ) and absolute vorticity (dashed, contour interval $2 \times$ $10^{-5} \mathrm{~s}^{-1}$ above $\left.10 \times 10^{-5} \mathrm{~s}^{-1}\right)$ at 0000 UTC 12 March 1993 .

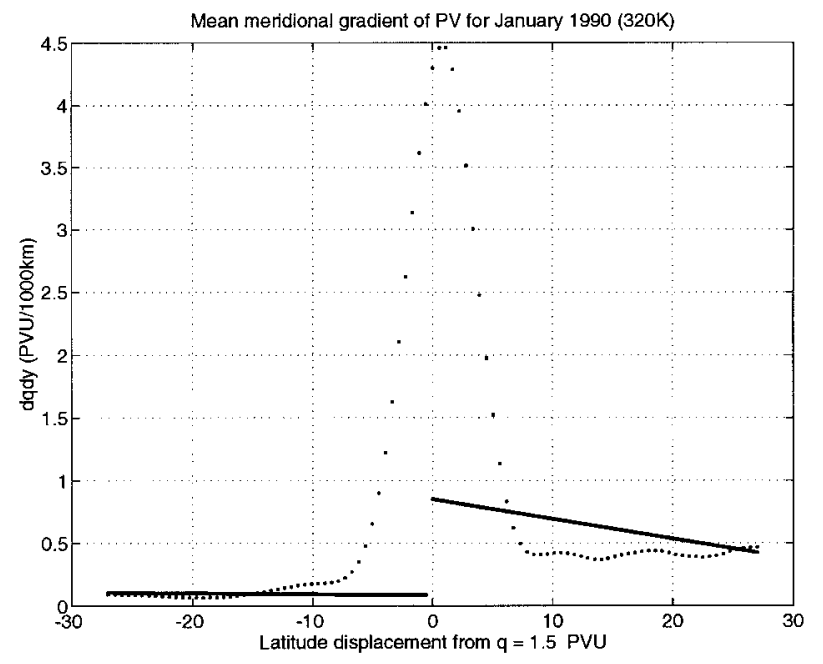

FIG. 3. $320 \mathrm{~K}$ "Lagrangian averaged" meridional gradient of PV for January 1991 (dotted curve) and latitudinal variation in PV accounting for variations in stratification between troposphere and stratosphere and planetary vorticity (solid curve).
The magnitude of the meridional gradient is seen to be maximized near the tropopause, while approximately $6^{\circ}$ lat north and south of the jet the gradients are an order of magnitude smaller. Ambaum (1997) has discussed how this concentration can arise from Rossby wave breaking events. For purposes of comparison, also shown in Fig. 3 is the meridional gradient in planetary vorticity $(\beta)$. The gradients of PV away from the tropopause are comparable to, or smaller than, the variations in PV associated with a typical stratification and $\beta$. By contrast, models that assume a constant tropospheric lapse rate, such as the classical Charney (1947) model, have a PV gradient of about $3 \beta$ (Sun and Lindzen 1994), and studies that assume such a gradient (such as Robinson 1989) consequently overestimate the dynamical importance of interior tropospheric PV gradients. Sun and Lindzen note that while the magnitude of PV gradients in the troposphere appear to be distinguishable from zero, these tropospheric gradients may in fact be exaggerated by limitations in the resolution and accuracy of observing systems. Be that as it may, advection of PV will, in general, generate significant PV anomalies at the tropopause level much more readily than at other levels, and the key upper-tropospheric dynamical process is the displacement and motion of the PV gradient, which characterizes the tropopause. 

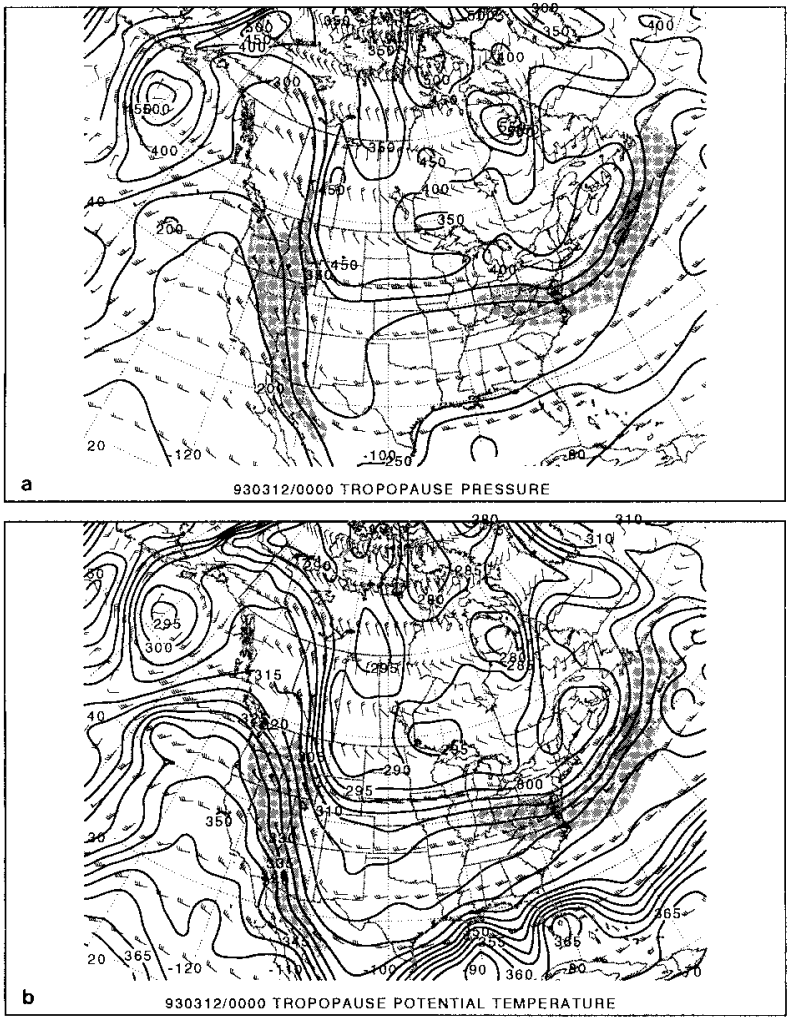

FIG. 4. Pressure (contour interval $50 \mathrm{mb}$ ), wind speed (light shading above $35 \mathrm{~m} \mathrm{~s}^{-1}$; dark shading, above $50 \mathrm{~m} \mathrm{~s}^{-1}$ ), and wind (as in Fig. 2) along the dynamic tropopause and (b) as in (a) except for potential temperature (contour interval $5 \mathrm{~K}$ ).

\section{c. Topography of the dynamic tropopause, and its relation to potential vorticity and winds}

The pressure topography of the tropopause (Fig. 4a) shows in two dimensions the structure seen in the cross section along $60^{\circ} \mathrm{W}$ (Fig. 1): a relatively high tropopause (low pressure) in the subtropics; a steeply sloping tropopause (with large gradients of pressure) in midlatitudes; and a nearly flat, relatively low tropopause near the pole. The preceding discussion suggests several close relationships between the topography of the dynamic tropopause and the distribution of tropospheric winds and temperatures.

Comparison with Fig. 2a confirms that a steeply sloped tropopause tends to correspond to an upper-level jet, with winds tending to be stronger in lower latitudes and where there is anticyclonic curvature rather than cyclonic curvature. The contours in Figs. $2 \mathrm{a}$ and $4 \mathrm{a}$ are similar in appearance. This is partly because they share certain isopleths: the locus of intersection of the 1.5 PVU surface with the $250-\mathrm{hPa}$ surface is indicated by the 250-hPa contour on the tropopause map and the 1.5 PVU contour on the constant-pressure map. Regions with a low tropopause, such as over northern Mexico in Fig. 4a, are therefore equivalent to regions of anomalously high upper-level PV (Fig. 2a).
We have shown that midtropospheric PV variations tend to be much weaker than variations near the tropopause, suggesting that the midtropospheric flow ought to be strongly associated with tropopause PV variations. A comparison of Figs. $4 \mathrm{a}$ and $2 \mathrm{~d}$ confirms this tendency. Even though the $500-\mathrm{hPa}$ surface is generally well below the tropopause, cyclonic (anticyclonic) 500-hPa vorticity is almost invariably associated with a locally low (high) tropopause.

The distribution of potential temperature on the tropopause may also be plotted (Fig. 4b); certain contours on this figure and Figs. $2 \mathrm{~b}$ and $2 \mathrm{c}$ will be identical. Cold (with respect to potential temperature) areas of the tropopause correspond to cyclonic PV anomalies and 500$\mathrm{hPa}$ vorticity maxima, and strong potential temperature gradients correspond to a steeply sloping tropopause and to $250-\mathrm{hPa}$ wind maxima.

Isobaric maps of upper-level PV are preferred by some over isentropic PV maps (IPV maps) because, on average, they lie closer to the tropopause and depict more of the significant PV anomalies. However, the dynamical information inherent in IPV maps is lost: PV is no longer advected by the horizontal wind alone, so $\mathrm{PV}$ and winds on isobaric surfaces do not give us a complete dynamical picture. On the other hand, as shown in the preceding paragraphs, several IPV maps are required to depict horizontal PV variations present on two or three constant-pressure maps.

A tropopause map such as Fig. 4a or Fig. 4b is superior to both because all PV anomalies on the tropopause are shown, on whatever pressure level or isentropic surface they lie. For example, the vorticity maximum over Alaska in Fig. 2d corresponds to a tropopause-level PV anomaly, as depicted by the high pressures of Fig. 4a and the low potential temperatures of Fig. 4b. This PV anomaly was too low in the atmosphere to appear in Figs. 2a and 2c. Furthermore, under adiabatic and frictionless conditions, tropopause potential temperature maps such as Fig. 4b may be used in the same way as IPV maps to deduce the evolution of the PV field. Each isentrope on a constant PV surface represents a concentrated PV gradient on the corresponding isentropic surface. To the extent that the flow is adiabatic, just as isentropic surfaces are material surfaces along which potential vorticity is advected, the dynamic tropopause is also a material surface along which potential temperature is advected.

\section{d. An Eady model view of tropospheric dynamics}

Potential temperature on the tropopause may be thought of in the same manner as potential temperature at the earth's surface. In the limit of infinite stratospheric static stability, they are equivalent, except for a change of sign: cold anomalies at the tropopause, like warm anomalies at the surface, are dynamically equivalent to positive PV anomalies. Juckes (1994) has demonstrated for the QG system that the analogy holds for realistic 
stratospheric static stability as well, except that the influence of a given potential temperature anomaly is weaker than it would be with infinite stratification. By combining a map of surface (or near-surface) potential temperature with a map of tropopause potential temperature, one obtains an "Eady model view" 5 of the dynamics of the troposphere, with the evolution of the tropospheric flow largely controlled by the distribution of potential temperature at its upper and lower boundaries.

The use of charts at only two levels to deduce the dynamics of the troposphere, while perhaps sounding extreme, is somewhat analogous to the traditional use of $500-\mathrm{hPa}$ and surface maps to diagnose tropospheric development. In a sense, the traditional method works because, as discussed earlier, most $500-\mathrm{hPa}$ vorticity extrema are associated with PV variations at the tropopause.

The diabatic generation of PV complicates the Eady model view of the tropospheric dynamics. To the extent that PV generation or destruction (or analysis error) takes place at the surface or the tropopause, it will appear as a nonadvective redistribution of potential temperature whose effects can be conceptually isolated from conservative processes. Frequently, though, diabatically generated distributions of PV within the lower troposphere (particularly those associated with latent heat release) can play an important role in the development of frontal waves (Eliassen and Kleinschmidt 1957; Hoskins and Berrisford 1988; Joly and Thorpe 1990; Davis 1992b). In such cases, the additional essential information about the lower-tropospheric PV distribution must be incorporated or provided as an additional chart.

\section{Dynamical representations of tropospheric PV}

In this section, we present and contrast various techniques for representing the upper- and lower-tropospheric PV distributions.

\section{a. Representations of the upper-tropospheric PV distribution: Tropopause maps}

The most common dynamical tropopause map is an analysis of potential temperature and winds along a surface of $\mathrm{PV}\left(Q=Q_{0}\right)$. To emphasize the fact that this analysis is being performed on a dynamical tropopause defined as a surface of constant Ertel PV, as opposed to a conventionally defined tropopause, we propose referring to the analysis of quantities along the dynamical tropopause as an isertelic analysis. Various means may be used to arrive at this analysis: superposition of is-

\footnotetext{
${ }^{5}$ For the Eady (1949) model, within which the pseudo-PV is constant, the dynamics of the fluid are completely determined by the distribution and evolution of potential temperature on the upper and lower boundaries.
}

entropes, direct analysis of potential temperature, and vertical interpolation of potential temperature to the tropopause surface. An additional type of tropopause analysis, which depicts the strength of the gradient on each isentropic surface, is also described below.

\section{1) CONTOUR SUPERPOSITION}

The method of contour superposition was suggested by K. Emanuel (1990, personal communication), and has been used by Bell and Bosart (1993). To motivate this technique, consider the isentropic PV analysis on the $325 \mathrm{~K}$ surface for a 24-h Eta Model forecast from 0000 UTC 27 March 1997 (Fig. 5a). The 1.5 PVU contour has been highlighted. This contour, the locus of points with $\theta=325 \mathrm{~K}$ and $Q=1.5 \mathrm{PVU}$, represents the intersection of the tropopause surface with the 325 $\mathrm{K}$ isentropic surface. Thus the contour may be regarded as the $325 \mathrm{~K}$ isentrope along the $1.5 \mathrm{PVU}$ surface. Similarly, the 1.5 PVU contour on the $335 \mathrm{~K}$ surface (Fig. $5 b)$ represents the $335 \mathrm{~K}$ isentrope along the tropopause. Superposing (overlaying) these two contours onto a single map, along with other 1.5 PVU contours from a set of equally spaced isentropic surfaces that span the middle and upper troposphere, results in an "analysis" of the potential temperature along the tropopause (Fig. 5c).

We note that instead of superposing contours, one might superpose "fill" or shade patterns. Starting from the highest isentropic surface, which intersects the tropopause, the technique would be to fill (shade) the values of PV greater than the defining value $(Q=1.5 \mathrm{PVU}$ in this case). Subsequent shadings are done on successively lower isentropic surfaces, with the results accumulating on a single chart. An example of such a chart is shown in Fig. $5 \mathrm{~d}$.

The primary advantage of this contour or fill superposition technique is that given an isentropic analysis of winds and pressure, the isentropic topography of the tropopause may be directly determined with no additional interpolation. Another advantage, as can be seen in Figs. 5c and 5d off the coast of Washington, is that the technique allows for isopleths of potential temperature to cross. Because the potential temperature is multivalued at particular locations, the superposition of isopleths technique allows for the depiction of tropopause folds. While the superposition of fill patterns provides a more direct visual impression of the configuration of the tropopause, it does so at the expense of loss of information near tropopause folds.

Low-level PV maxima with values exceeding 1.5 PVU may also be present in the analysis. These maxima are not associated with tropopause undulations, but rather they may be associated with diabatically "generated" interior PV. While these low-level PV variations are often dynamically significant, contour superposition creates an arbitrary thresholding of the values depicted-maxima of 1.5 PVU or less are not contoured in the analysis. A more important disadvantage of this 

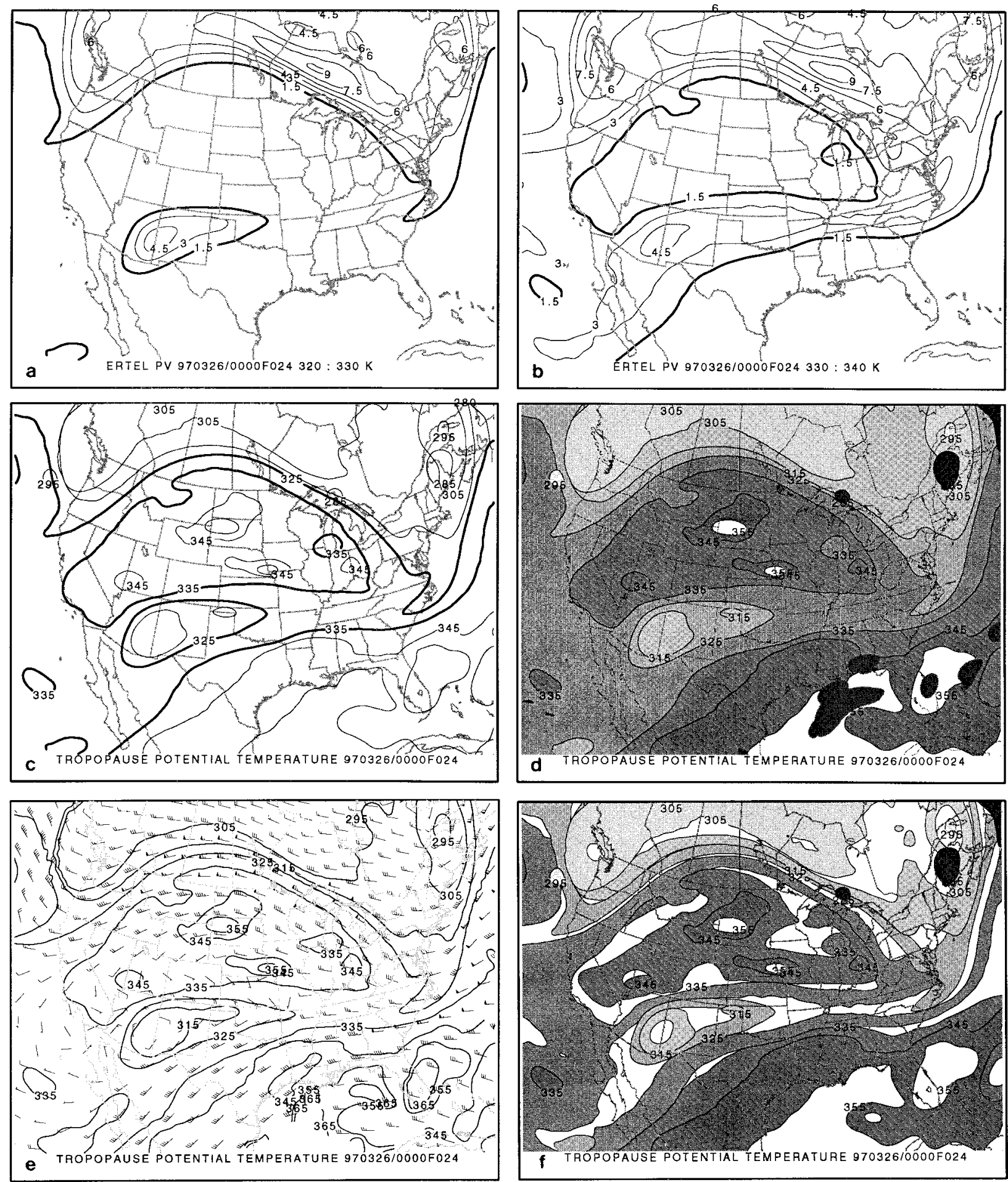

FIG. 5. Ertel PV (contour interval 1.5 PVU with the 1.5 PVU contour heavy) from a 24-h Eta Model forecast at 0000 UTC 26 March 1997 on the (a) $325 \mathrm{~K}$ isentropic surface and (b) $335 \mathrm{~K}$ isentropic surface. Tropopause potential temperature analyses using (c) contour superposition method (contour interval $10 \mathrm{~K}$ ), (d) superposition of shade pattern method (contour and shade interval $10 \mathrm{~K}$ ), and (e) interpolation method (contour interval $10 \mathrm{~K}$ ) for same time in (a). (f) Analysis of the 1.5 to 3 PVU tropopause band every $10 \mathrm{~K}$ using superposition of shade pattern method for same time in (a). 
technique is that it is purely graphical. Because the contours were simply superposed onto a single chart, one does not have gridpoint values of atmospheric variables along the tropopause for diagnostic calculations.

\section{2) VERTICAL INTERPOLATION}

A more common way to produce a tropopause map from a gridded dataset is to vertically interpolate potential temperature onto the tropopause surface. Within each grid column, PV is computed at successive vertical levels until the threshold tropopause value is crossed. The vertical level of the tropopause is determined by interpolation, and potential temperature is then interpolated to the level of the tropopause. An example of such a map is seen in Fig. 5e.

The primary advantage of this technique over the method of contour superposition is that other variables, such as pressure and wind, may also be interpolated to the tropopause level, producing a complete two-dimensional gridded analysis of meteorological variables on the tropopause. However, the results of the analysis depend on whether the search for the tropopause proceeds upward or downward. If done from below, the search should be initiated at some level well above the ground, such as $650 \mathrm{hPa}$, to avoid patches of high low-level PV (PV greater than 1.5 PVU) appearing in the analysis. In tropopause folds, a search from below will first encounter the tropopause at a different level than a search from above. The difference between the two isertelic height fields so obtained is zero except where the tropopause is folded, and the magnitude of the difference gives the vertical extent of the fold. The discontinuity at vertical or folded tropopauses is poorly resolved by the gridded analysis and may lead to contouring difficulties (such as the jagged contours off the coast of Washington) unless the interpolated data is then smoothed horizontally.

\section{3) Direct Calculation}

A WMO tropopause analysis may be constructed directly from rawinsonde data by recording the potential temperature at the tropopause level at each sounding site and analyzing the potential temperature objectively or subjectively. ${ }^{6}$ A similar procedure may be followed for analyses of the dynamic tropopause, following a method first described by Nielsen (1988).

Briefly, the direct method applies the Bellamy (1949) triangle method to compute the mean vorticity within a given isentropic layer, and combines this information with the mean pressure thickness of the layer to obtain the mean PV for the triangle bounded by the three sta-

\footnotetext{
${ }^{6}$ Defant and Taba (1957) published the first hemispheric map of the topography of the tropopause using a rawinsonde-based definition of the tropopause.
}

tions. The calculation is repeated in successive isentropic layers, and the tropopause surface identified as in the vertical interpolation method. A complete set of tropopause "observations" may be generated from a set of rawinsonde observations using techniques such as those described by Ceselski and Sapp (1975) and Schaefer and Doswell (1979). This method is more unwieldy than other methods, but has the advantage of allowing a subjective analysis of the distribution of potential temperature on the tropopause. The analyst may incorporate conceptual models of the tropopause, such as tropopause discontinuities near jet streams, into the analysis, in principle producing a more realistic analysis than is possible with other methods.

\section{4) TROPOPAUSE BAND SUPERPOSITION}

The interpretation of most tropopause maps assumes a strong PV gradient in the vicinity of the tropopause. However, if the PV analysis is noisy and the tropopause is nearly flat, it can be difficult to tell from an isertelic analysis whether potential temperature variations represent significant PV anomalies or minor variations in vorticity or stratification. To avoid this ambiguity, Nielsen-Gammon (1995) developed an alternative type of tropopause map that represents the tropopause as a transition zone or band with values of PV between 1.5 and 3 PVU.

The method of construction of a tropopause band map is similar to the contour superposition method, except that shaded bands from each isentropic layer, representing the position of PV values within the tropopause transition zone, are superposed (Fig. 5f). The resulting map indicates not only the distribution of potential temperature within the tropopause layer, but also the magnitude of the PV gradient at the tropopause: the isentropic PV gradients are inversely proportional to the width of the tropopause PV bands. A disadvantage of this type of map is that some bands may become obscured or hidden as successive bands are added to the map, resulting in a loss of information.

\section{b. Representations of the lower-tropospheric PV}

The lower-tropospheric PV distribution is composed of two elements-the Ertel PV and the (near-) surface potential temperature.

\section{1) INTERIOR PV EXTREMA}

Distinct low-level PV maxima occasionally form due to diabatic processes associated with either surface cooling (creating an inversion) or latent heat release in regions of ascent. The PV maxima associated with radiative cooling are transitory-usually disappearing the next morning when near-surface air heats up. Other surface-based inversions, such as may be produced by warm air passing over cold water (Neiman et al. 1990) 


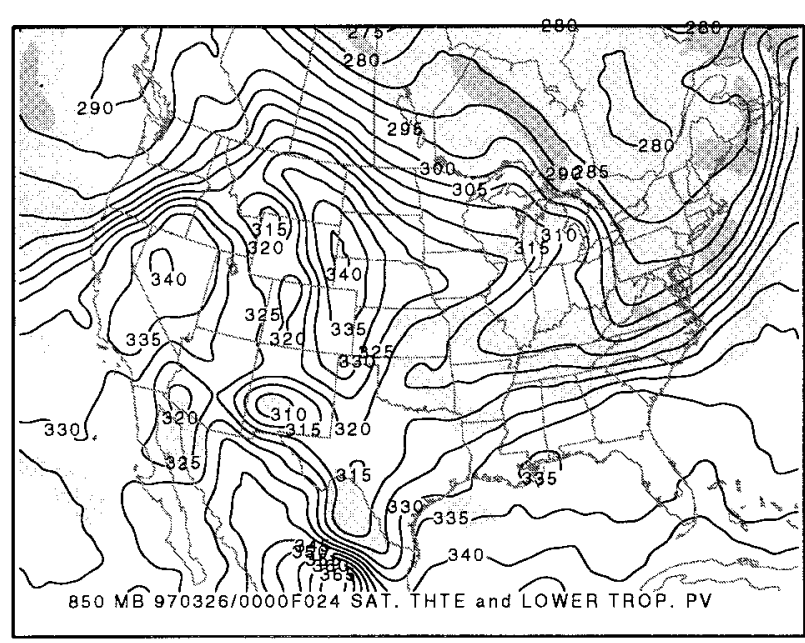

FIG. 6. Analysis of $850-\mathrm{hPa}$ saturated equivalent potential temperature (contour, interval $5 \mathrm{~K}$ ) and 700-850-hPa-layer averaged Ertel PV (shaded; light shading greater than 0.5 PVU, dark shading greater than $1 \mathrm{PVU}$ ) for same time as in Fig. 5

or fog in interior basins such as California's Central Valley, have little effect on the dynamics of the air above them. The maxima associated with a vertical redistribution of PV by latent heat release tend to be deeper, can remain coherent for several days, and have been shown to play a role in surface cyclogenesis. Joly and Thorpe (1990) suggest that mesoscale frontal wave cyclones are the result of an instability arising from an interaction of diabatically generated PV anomalies with a surface front. It is desirable to keep track of the existence of these deep interior maxima as they serve as signatures of the diabatic processes that created them, and as they may be dynamically important in the development of tropospheric weather systems.

Various methods of depicting interior tropospheric PV distributions have been employed (Hoskins and Berrisford 1988; Hakim et al. 1995). Hoskins and Berrisford analyze the PV (above 0.25 PVU) on the $300 \mathrm{~K}$ surface. The minimum threshold value taken by Hoskins and Berrisford allows one to distinguish the interior anomalies from the essentially homogeneous ambient tropospheric PV. A disadvantage of this approach is that interior anomalies may be created on a surface other than $300 \mathrm{~K}$, and would not be seen. Hakim et al. (1995) plot the tropospheric average PV (PV averaged from $1000 \mathrm{hPa}$ to the tropopause level). This approach allows for the identification of the location of the interior PV, but does not distinguish upper- and lower-tropospheric maxima, and may mask instances in which latent heating redistributes PV in the vertical (while simultaneously conserving a volume integral of the PV).

An alternative approach, preferred here, is to plot the lower-tropospheric (850-700 hPa) vertically averaged PV (Fig. 6). Isobaric coordinates are acceptable because $\mathrm{PV}$ anomalies in this part of the troposphere are generally associated with nonconservative effects. The 700-
hPa level is close to, but below, the typical level of maximum heating, so that the positive anomalies generated by latent heat release will not be masked by the negative anomalies generated above. The bottom level of the layer, here $850 \mathrm{hPa}$, should correspond to the level of depiction of near-surface potential temperature, discussed below.

\section{2) NEAR-SURFACE POTENTIAL TEMPERATURE}

Dynamical considerations suggest that the surface or boundary potential temperature would be the variable to analyze in an "Eady representation" of the troposphere. Because near-surface air experiences diabatic heating due to its contact with the ground and to fluxes of sensible heat, potential temperature is not conserved at the earth's surface. Consequently, in keeping with the desire to construct analyses of conserved variables, a different approach is required.

As discussed by HMR, an analysis of potential temperature at the top of the boundary layer might be a suitable surrogate for the surface potential temperature. In general, however, analyses at such a level are not generally available, and cannot be constructed from conventional gridded analyses. A better approach would be to consider the potential temperature along some lowertropospheric pressure surface. The surface should be high enough to be removed from the nonconservative processes described above-but any constant pressure surface is subject to two additional sources or sinks of potential temperature: latent heat release and vertical advection of potential temperature. Both of these sources and sinks increase with importance with height above the ground. Over oceanic regions, the 925-hPa isobaric surface is acceptable, whereas over mountainous regions such as the Rocky Mountains, a higher isobaric surface like the $700-\mathrm{hPa}$ surface is required. A good compromise level for most applications seems to be $850 \mathrm{hPa}$.

We note that an equally suitable variable to plot would be the saturated equivalent potential temperature, $\theta_{e}^{*}$ (Fig. 6). ${ }^{7}$ This variable is proportional to potential temperature and is similarly conservative. The equivalent potential temperature, $\theta_{e}$, on the other hand, is not a thermodynamic state variable. To invert a distribution of $\theta_{e}$, an a priori knowledge of the relative humidity distribution would be required. However, as will be shown below, variations in $\theta_{e}$ can be used to infer the potential for and consequences of convection.

\footnotetext{
${ }^{7}$ When using $\theta_{e}^{*}$ at the surface, the appropriate PV to consider is the saturated moist $\mathrm{PV}, q_{e}^{*}\left(=\alpha \boldsymbol{\omega}_{a} \cdot \boldsymbol{\nabla} \theta_{e}^{*}\right)$, which is conserved in saturated regions and is nearly zero in many regions of saturated ascent (Emanuel 1985). To the extent that $q_{e}^{*}$ is zero everywhere, all the information on the quasi-balanced flow is contained in the near-surface and tropopause $\theta_{e}^{*}$ distributions.
} 

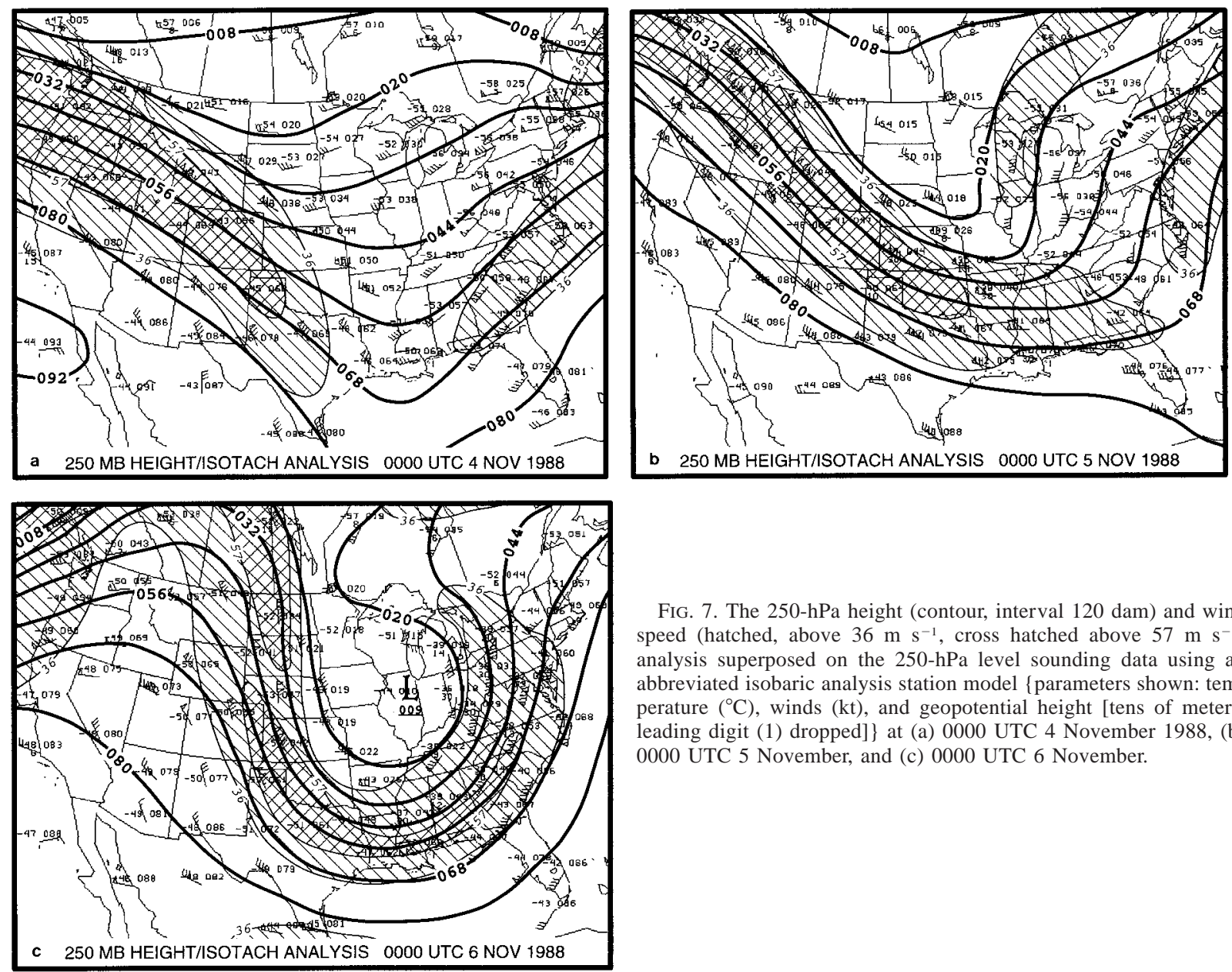

FIG. 7. The 250-hPa height (contour, interval 120 dam) and wind speed (hatched, above $36 \mathrm{~m} \mathrm{~s}^{-1}$, cross hatched above $57 \mathrm{~m} \mathrm{~s}^{-1}$ ) analysis superposed on the $250-\mathrm{hPa}$ level sounding data using an abbreviated isobaric analysis station model \{parameters shown: temperature $\left({ }^{\circ} \mathrm{C}\right)$, winds $(\mathrm{kt})$, and geopotential height [tens of meters, leading digit (1) dropped] $\}$ at (a) 0000 UTC 4 November 1988, (b) 0000 UTC 5 November, and (c) 0000 UTC 6 November.

\section{Case study: November 1988}

This case study uses tropopause maps constructed from gridded sounding data. It features dramatic examples of a strong upper-level jet, the development of a tropopause fold, the formation of an intense upperlevel trough, and the effects of deep moist convection.

\section{a. Conventional analyses}

The basic upper-level development is shown in a series of 250-hPa maps (Fig. 7). At 0000 UTC 4 November 1988 (Fig. 7a) or 04/00 (for brevity, the date and time will be abbreviated henceforth as day/hour), a strong northwesterly upper-level jet extends from the Pacific Northwest into Texas, a weak trough is located over the central gulf coast, and a southwesterly jet originates over the Southeast. The northwesterly jet is so strong that most wind observations are missing, the rawinsondes having traveled beyond the horizon. Lower-level winds, gradient wind balance, and NMC analyses suggest that the maximum wind speed approaches $75 \mathrm{~m} \mathrm{~s}^{-1}(150 \mathrm{kt})$.

One day later (Fig. 7b), the jet has become cyclon- ically curved and extends all the way to Florida. The gulf trough and downstream jet have moved to the Carolinas and the western Atlantic, and a third jet has appeared over the western Great Lakes and southeastern Canada.

By $06 / 00$ (Fig. 7c), the $250-\mathrm{hPa}$ analysis features a massive closed upper-level low over the Midwest. The strong jet now extends all the way around the base of the closed low, from Nebraska across the gulf coast to southern Ontario. The jets formerly over the Atlantic and the upper Great Lakes have moved almost entirely beyond the margins of the map. This evolution in two days from nearly zonal flow across the United States to a high-amplitude ridge-trough pattern is unusually rapid.

The sequence of events mirrors the schematic diagram of a propagating jet streak produced by M. Shapiro and reproduced as Fig. 19 of Keyser and Shapiro (1986). Between 04/12 and 05/00, the jet streak extends from the ridge to the developing downstream trough, and as discussed by Keyser and Shapiro, the associated cold advection within the jet streak (not shown) favors a 
crossjet ageostrophic circulation configured to produce a tropopause fold. The observed folding was quite pronounced, as will be shown below with the tropopause maps.

Twelve-hourly surface maps beginning at 04/12 are provided in Fig. 8. Frontal positions are not shown but may be inferred from the analyses of pressure and $\theta_{e}$, which is plotted rather than $\theta$ or $\theta_{e}^{*}$ to aid in the interpretation of moist convection (below). The surface analyses depict an intensifying frontal cyclone, which had just become organized at 04/12 (Fig. 8a) and undergoes its most rapid deepening between 05/12 (Fig. 8c) and 06/00 (Fig. 8d). Precipitation is not particularly widespread with this system, but thunderstorms marched across the Southeast ahead of the cold front, extending as far north as Illinois at 04/12 and producing 23 tornadoes and one fatality (NCDC 1988).

The rather complex initial distribution of $\theta_{e}$ is due in part to cold-air damming along the southern Appalachians (Bell and Bosart 1988). At 05/00 (Fig. 8b), the narrow tongue of high $\theta_{e}$ extending toward the cyclone center has disappeared, and the surface thermal structure is anything but classical as the cyclone is located between baroclinic zones to its north and south. During the following $24 \mathrm{~h}$, the cyclone circulation ingests both warm air from the southern United States and cold air from Canada, and the rapid deepening between 05/12 and $06 / 00$ coincides with the amplification of the surface thermal wave and the onset of occlusion.

\section{b. Tropopause maps}

The tropopause maps for this case (Fig. 9) were produced by the contour superposition method using Barnes objective analyses (Koch et al. 1983) of winds and pressures on isentropic surfaces. Major features appearing on the tropopause maps are discussed in roughly chronological sequence.

\section{1) The tropopause DiscontinUity Within A STRONG JET STREAK}

As discussed in section 2, strong upper-level jets are typically associated with a nearly vertical tropopause, which on a dynamic tropopause map appears as a near discontinuity in potential temperature or pressure. At 04/00 (Fig. 9a), such a vertical tropopause curves anticyclonically from the Oregon coast to north Texas, coinciding with the location and alongstream extent of the jet streak (Fig. 7a). This tropopause discontinuity, in excess of $40^{\circ} \mathrm{C}$, is unusually large, as are the wind speeds within the jet streak itself. The isotherms are almost superposed, and the $325-\mathrm{K}$ isotherm is located slightly south of higher-valued isotherms over Oregon and Idaho, implying a small tropopause fold. (The fold extends all the way to southeastern Colorado at a slightly higher level, as indicated by the positions of the 330$\mathrm{K}$ and $335 \mathrm{~K}$ contours.) By contrast, the jet streak over the Southeast appears on the tropopause map as a less concentrated potential temperature gradient, which is weaker (a potential temperature difference of about $15^{\circ} \mathrm{C}$ ), implying a smoothly sloping tropopause rather than a tropopause break. Wind speeds within this jet streak are correspondingly weak.

\section{2) THE INTERACTION OF TWO UPPER-LEVEL TROUGHS}

Upper-level troughs are associated with locally cold tropopauses, which may appear as closed temperature contours or as waves in the isentropes. The moderate trough over the gulf coast and the weaker trough over Nebraska at 04/00 are both waves (cf. Figs. 7a and 9a). As with the jet streaks, the relative strength of these troughs is related to the relative magnitude of the temperature perturbations. According to the tropopause map, the PV gradients that these contours represent are located at different isentropic levels: $330-350 \mathrm{~K}$ for the eastern trough and 320-325 K for the western trough. From this, one may deduce that the two troughs have the potential to superimpose, producing a particularly strong trough, if the vertical wind shear and propagation velocities of the waves are such that the western wave is moving southeastward relative to the eastern wave. Such a wave merger is not possible for two waves located along the same isentropic surfaces, and the two cases are difficult or impossible to distinguish using conventional analyses.

As it turns out, a rather different evolution takes place, as the eastern trough lifts out and the jet streak plunges southward to replace it. According to PV thinking, two positive upper-level vortices, such as the two troughs, should act to advect each other counterclockwise (Hakim et al. 1996), and this may be partly responsible for the observed evolution. Additionally, since both troughs are waves embedded within a north-south tropopause potential temperature (PV) gradient, Rossby wave dynamics suggest that the combined wave should be downward propagating, causing intensification of the western trough and weakening of the eastern trough. This is so because the eastern trough "induces" northerlies within the western trough, amplifying it, whereas the western trough induces southerlies within the eastern trough, weakening it.

\section{3) The EVOlution of AN ENORMOUS tropopause FOLD}

During the period of interest, the long, narrow tropopause fold present beneath the jet streak at $04 / 00$ evolves into a massive fold covering at least half of 10 states and smaller portions of 10 others. The presence of significant folds at later times is suggested by the evolution of Fig. 9 from an orderly set of contours to maps resembling the "spaghetti plots" often used to display ensemble forecast output. 

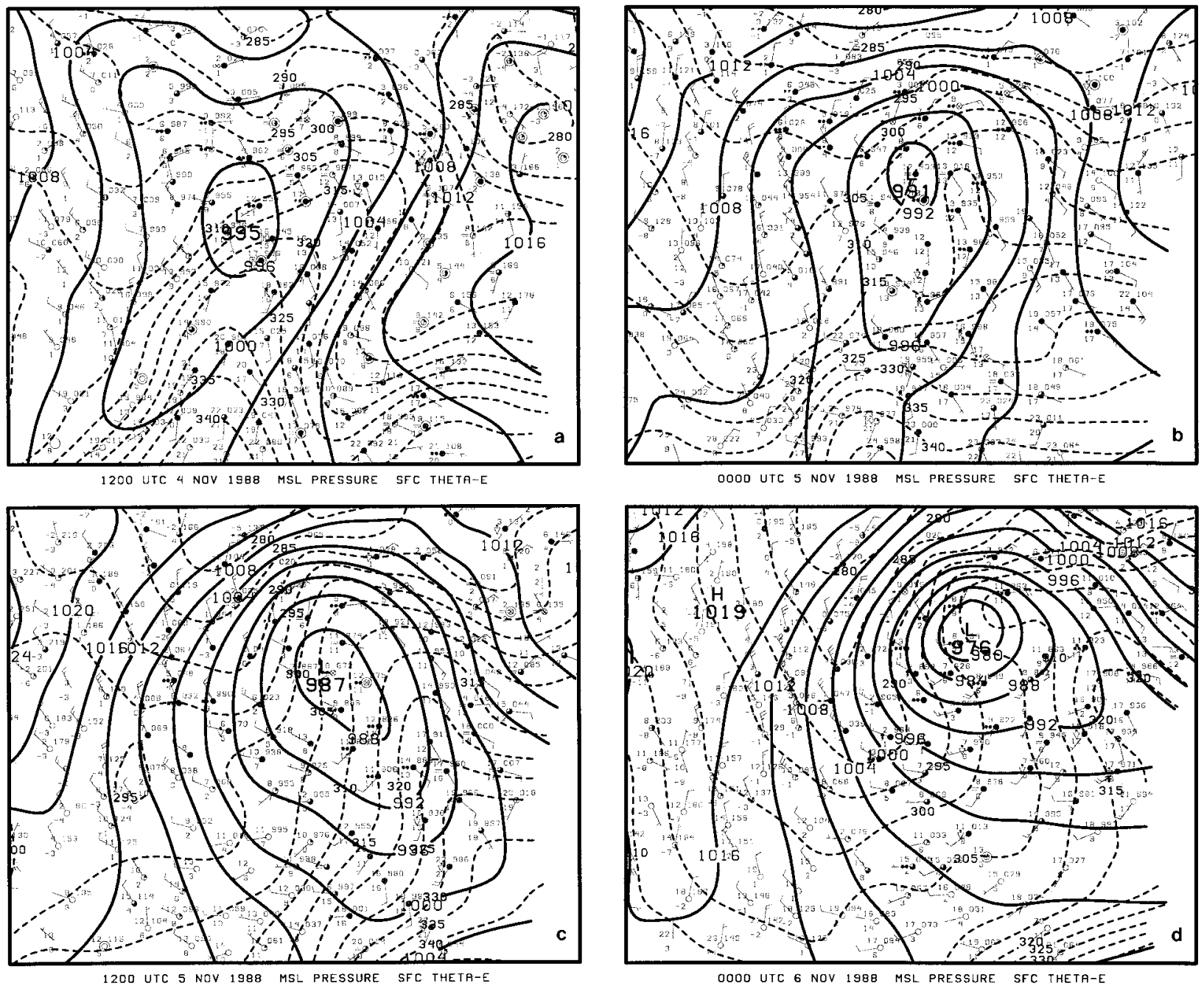

FIG. 8. Surface analysis of mean sea level pressure (solid contour, interval $4 \mathrm{hPa}$ ) and surface equivalent potential temperature (dashed, interval $5 \mathrm{~K}$ ) superposed on surface plot of station data using an abbreviated conventional station model [parameters shown: temperature $\left({ }^{\circ} \mathrm{C}\right)$, dewpoint temperature $\left({ }^{\circ} \mathrm{C}\right)$, mean sea level pressure (tenths of $\mathrm{hPa}$, leading digits dropped), wind (kt), and weather symbols] at $(\mathrm{a})$ 1200 UTC 4 November 1988, (b) 0000 UTC 5 November, (c) 1200 UTC 5 November, and (d) 0000 UTC 6 November.

Two distinct segments of the tropopause fold are present; one is centered on the $325 \mathrm{~K}$ level and the other is centered on the $310 \mathrm{~K}$ level. The $325 \mathrm{~K}$ fold, as described above, was located over Oregon and Idaho at 04/00. By 04/12 (Fig. 9b), it has progressed along the jet streak and extends from southwestern Wyoming to west-central Oklahoma. During the next $12 \mathrm{~h}$, this segment of the fold increases dramatically in width. At 05/ 00 (Fig. 9c), the tropopause is on the $350 \mathrm{~K}$ surface over central Arkansas and on the $325 \mathrm{~K}$ surface over the Louisiana coast. Thus, stratospheric air extends beneath tropospheric air from central Arkansas to southern Louisiana, a distance of over $500 \mathrm{~km}$. Along the $335 \mathrm{~K}$ and $340 \mathrm{~K}$ surfaces, the folded tropopause extends to southwestern Georgia; this portion of the fold remains small and will not be discussed further.

Between 05/00 and 05/12 (Fig. 9d), the fold retains its half-moon shape while rotating around the base of the trough and intensifying. Progressively thicker layers of the stratosphere are drawn into the fold: by $05 / 12$, stratospheric air on the $315 \mathrm{~K}, 320 \mathrm{~K}, 325 \mathrm{~K}$, and 330 $\mathrm{K}$ surfaces extend several hundred kilometers beneath and south of the tropospheric air on the $340 \mathrm{~K}, 345 \mathrm{~K}$, and $350 \mathrm{~K}$ surfaces, and by 06/00 (Fig. 9e), $310 \mathrm{~K}$ stratospheric air has been drawn into this portion of the fold. Although the eastern edge of the fold is not resolved by the rawinsonde network, this fold appears to be up to $600 \mathrm{~km}$ wide (from western North Carolina to beyond the Gulf Stream) and about $2000 \mathrm{~km}$ long (from north of Lake Ontario to southern Alabama), for a total area of about $6 \times 10^{5} \mathrm{~km}^{2}$.

Two soundings through the heart of the fold, at Centerville, Alabama, at 05/12 and at Charleston, South Carolina, at 06/00 (Fig. 10) confirm the dramatic nature of the fold. At Centerville, stratospheric air is present from $500 \mathrm{hPa}$ to $375 \mathrm{hPa}$, with tropospheric air over- 


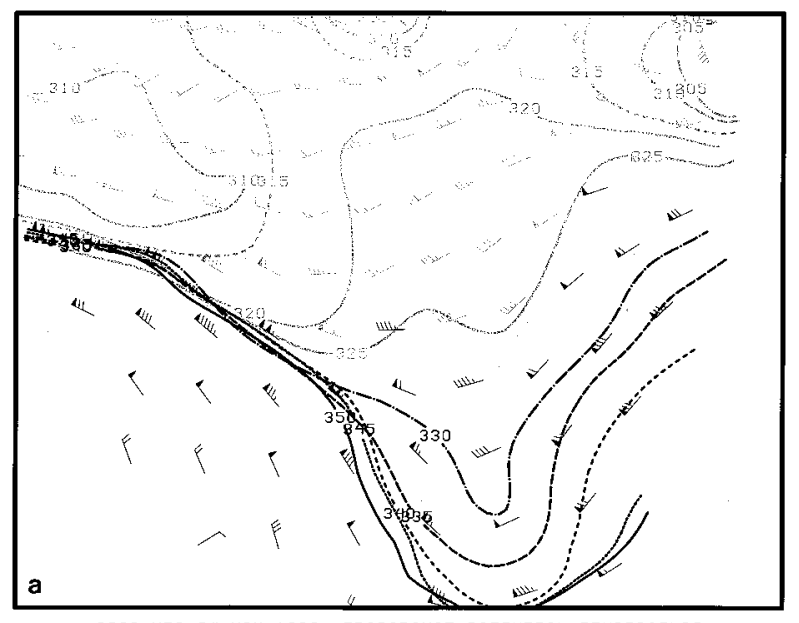

OOOO UTC 04 NOV 1988 TROPOPAUSE POTENTIAL TEMPERATURE

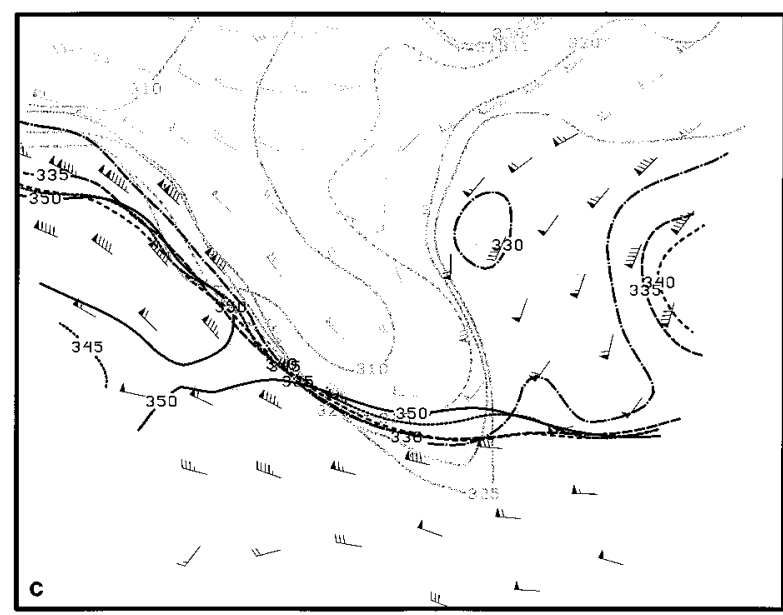

OO00 UTC O5 NOV 1988 TROPOPAUSE POTENTIAL TEMPERATURE

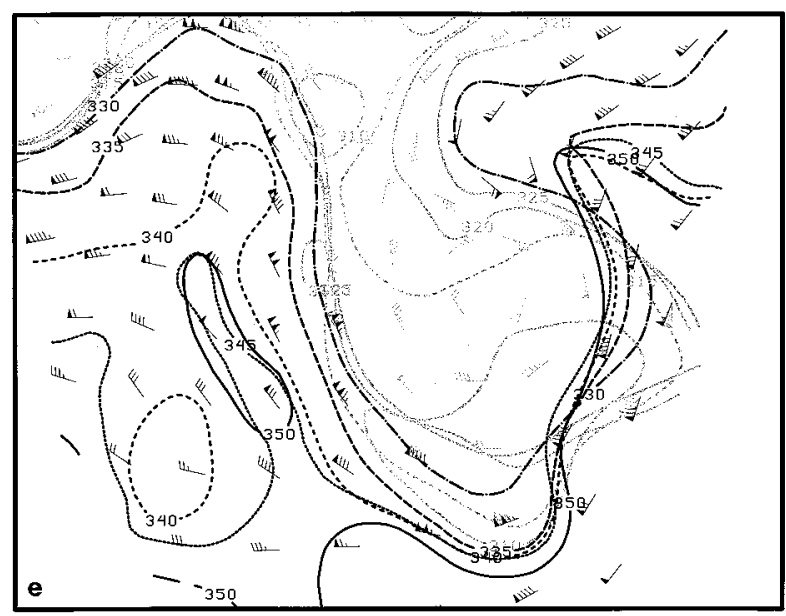

O000 UTC O6 NOV 1988 TROPOPRUSE POTENTIAL TEMPERATURE

lying it to $150 \mathrm{hPa}$. The fold is $35 \mathrm{~K}$ thick. At Charleston, the fold is closer to the ground, between 600 and $500 \mathrm{hPa}$, with $335 \mathrm{hPa}$ of tropospheric air overlying it. The tropopause maps and soundings agree on which

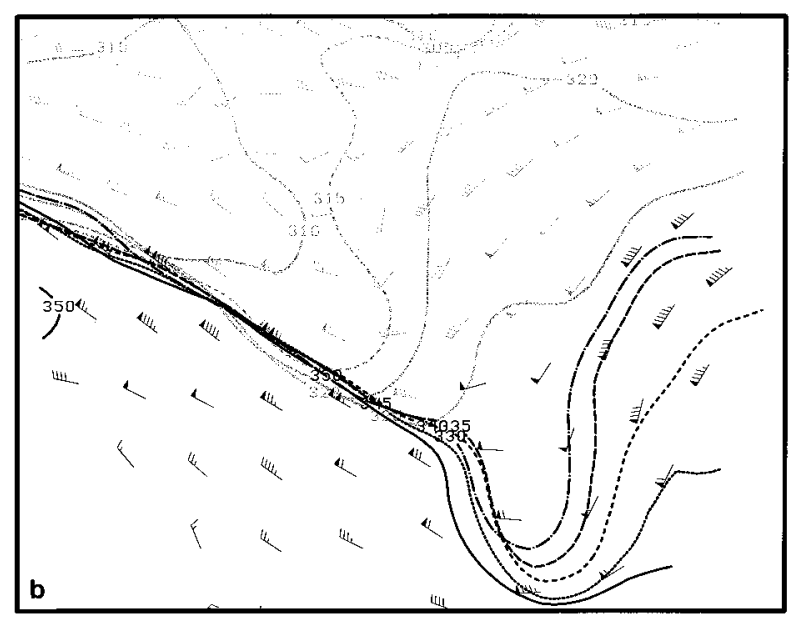

1200 UTC O4 NOV 1988 TROPOPAUSE POTENTIAL TEMPERATURE

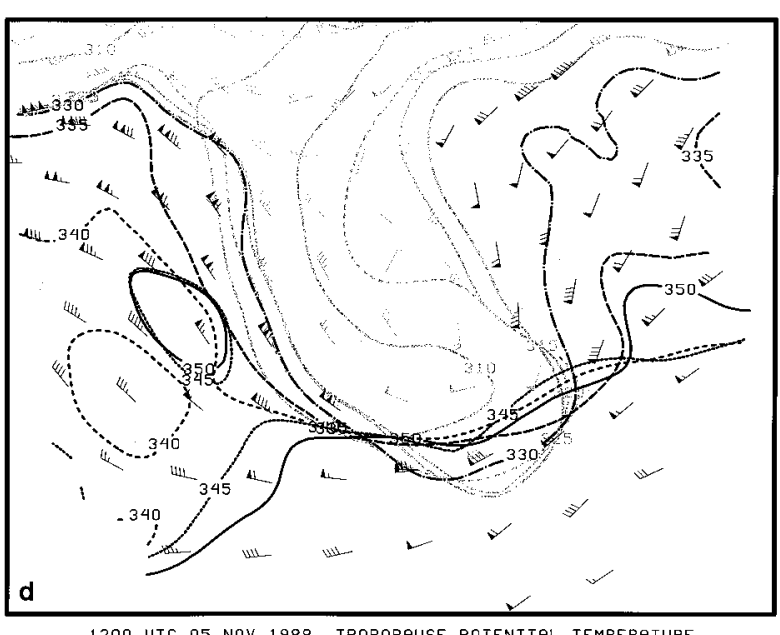

1200 UTC 05 NOV 1988 TROPOPAUSE PDTENTIAL TEMPERATURE

FIG. 9. Tropopause potential temperature (contour interval $5 \mathrm{~K}$ from $305 \mathrm{~K}$ to $350 \mathrm{~K}$ ) and wind (short barb $=2.5 \mathrm{~m} \mathrm{~s}^{-1}$, long barb $=5$ $\mathrm{m} \mathrm{s}^{-1}$, pennant $=25 \mathrm{~m} \mathrm{~s}^{-1}$ ) at (a) 0000 UTC 4 November 1988, (b) 1200 UTC 4 November, (c) 0000 UTC 5 November, (d) 1200 UTC 5 November, and (e) 0000 UTC 6 November.

isentropic levels are contained within the tropopause fold.

Farther upstream, a second fold is present in which the $325 \mathrm{~K}$ surface is within the troposphere and strat- 
$881106 / 000072208$ CHS

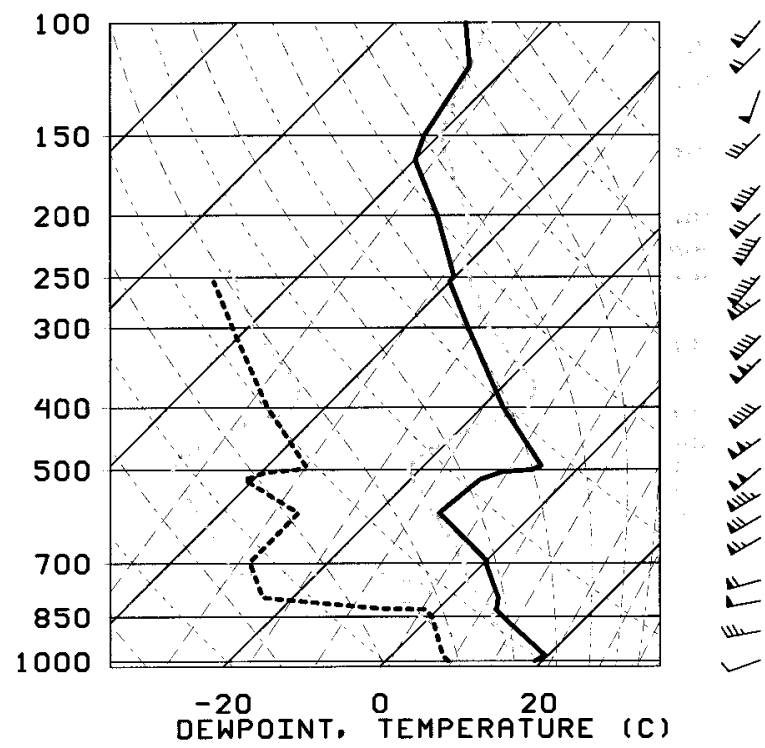

FIG. 10. Skew $T$ diagram (temperature solid, degrees Celsius; dewpoint temperature dashed, degrees Celsius) and sounding winds (kt) for CKL (Centerville, AL) (gray) at 1200 UTC 5 November 1988 and for CHS (Charleston, SC) (black) at 0000 UTC 6 November.

ospheric air is folded beneath it, primarily along the 310 $\mathrm{K}$ surface. The eastern portion of the fold first appears at $04 / 12$ from the Washington-Oregon coast to central Idaho, and the rest of the fold comes onshore during the following $24 \mathrm{~h}$. At $05 / 12$ the entire fold is visible in Fig. 9, extending from central Alberta (where the 310 and $330 \mathrm{~K}$ contours first cross) to extreme eastern Texas (where the 315 and $325 \mathrm{~K}$ contours uncross themselves), a distance of $2800 \mathrm{~km}$. This fold is not as thick as the first fold; only stratospheric air along the $310 \mathrm{~K}$ and $315 \mathrm{~K}$ surfaces is folded, beneath tropospheric air between $320 \mathrm{~K}$ and $330 \mathrm{~K}$. Remarkably, the fold continues to expand, stretching from extreme northern Saskatchewan to central Georgia at $06 / 00$, where it overlaps with the first fold.

The combined tropopause fold, at $06 / 00$, is larger than any fold over North America we have seen or are aware of. The fold extends from Quebec to the Atlantic, the Gulf of Mexico, and north again to the southern border of the Northwest Territories, a total length of $8400 \mathrm{~km}$ !

\section{4) The EFFECT OF DEeP CONVECTION ON THE TROPOPAUSE}

Tropopause maps, in combination with maps of lowlevel $\theta_{e}$, may be used to infer the potential for deep convection. Except when folded, the tropopause is generally high enough or cold enough that the difference between tropopause $\theta$ and tropopause $\theta_{e}^{*}$ is no more than a few degrees and can be neglected for qualitative purposes. The difference between low-level $\theta_{e}$ and tropopause $\theta$ therefore provides a "poor man's" lifted index (Bosart and Lackmann 1995), with the advantage over conventional lifted indices that both low-level $\theta_{e}$ and tropopause $\theta$ are approximately conserved and are unchanged by vertical motion. Thus, the advection of low-level $\theta_{e}$ and tropopause $\theta$ can be independently inferred from the distribution of winds and future lifted indices can be predicted.

At 04/12, the surface map (Fig. 8a) shows thunderstorms from Ohio to Missouri, and the tropopause map (Fig. 9a) indicates the likelihood of continued deep convection. Surface $\theta_{e}$ 's between $320 \mathrm{~K}$ and $335 \mathrm{~K}$ extend from central Illinois southward through Arkansas, while aloft, the $325 \mathrm{~K}$ contour overlays the same area. Furthermore, the potential instability should be rapidly increasing: there are southerly winds and positive $\theta_{e}$ advection at the surface, while the tropopause maps from $04 / 00$ and $04 / 12$ indicate that tropopause temperatures below $315 \mathrm{~K}$ should reach the area within $12 \mathrm{~h}$. This inference is based on the advecting winds at the leading edge of the mass of $315 \mathrm{~K}$ air and is corroborated by the observed motion of the $315 \mathrm{~K}$ air between $04 / 00$ and $04 / 12$.

As mentioned previously, this storm was the occasion of a tornado outbreak, so deep convection did indeed persist. Here, we wish to emphasize the evidence of, and effect of, the deep convection at the tropopause level. In particular, compare the tropopause maps for 04/12 (Fig. 9b) and 05/00 (Fig. 9c). A closed $330 \mathrm{~K}$ contour has appeared at $05 / 00$, and the $325 \mathrm{~K}$ contour, which had stretched along the Ohio River Valley, extends as far north as James Bay. Neither of these changes can have been produced by advection, given the wind patterns at these times. Instead, this warming of the tropopause has been produced by high $\theta_{e}$ air $(320 \mathrm{~K}$ to $335 \mathrm{~K}$ ) ascending in deep moist convection and being expelled at the tropopause level. The warming of the dynamic tropopause is equivalent to the destruction of PV at tropopause level by the vertical gradient of diabatic heating.

The sounding from Monett, Missouri (Fig. 11), taken at $04 / 12$ within the tongue of warm, moist low-level air, shows the deep instability present that morning. The moist parcel just above the surface has a $\theta_{e}$ of $333 \mathrm{~K}$ and a 500-hPa lifted index of -7 . Soundings farther to the east feature deeper moisture, but have already been influenced by convection.

Were convection to act to stabilize this sounding, low levels would need to cool and the air from $650 \mathrm{hPa}$ to the tropopause would have to warm. To the east, where an ample supply of moisture is present, the only available means of stabilization is convective overturning, which would warm the upper troposphere to the moist adiabat of a lifted parcel, either through compensating subsidence or by replacing the upper-tropospheric air with boundary layer air (Bosart and Nielsen 1993), while simultaneously replacing the boundary layer air 
with evaporatively cooled downdrafts. Since the lifted index at $300 \mathrm{hPa}$ is also -7 , this means that the tropopause would warm by as much as $7 \mathrm{~K}$ in response to widespread deep moist convection. Indeed, the warm tropopause at $05 / 00$ over the Ohio Valley and the Great Lakes has potential temperatures between $320 \mathrm{~K}$ and $332 \mathrm{~K}$, in close agreement with low-level $\theta_{e}$ 's in the area of thunderstorm activity just to the south.

Also shown in Fig. 11 is a sounding at 05/00 from Sault Ste. Marie, Michigan, downstream of the area of convection. At this location, the tropopause is $5-10 \mathrm{~K}$ warmer than can be explained by adiabatic advection. Horizontal upper-level trajectories would place the tropopause air in the vicinity of Monett at 04/12, where the tropopause was near $300 \mathrm{hPa}$. Here, at Sault Ste. Marie, the tropopause is at $200 \mathrm{hPa}$. Of particular significance is the layer of air between 200 and $300 \mathrm{hPa}$, which features winds up to $20 \mathrm{~m} \mathrm{~s}^{-1}$ (40 kt) stronger than winds at other levels. We conclude that this air represents outflow from the widespread convective activity (Fritsch and Maddox 1981), aided by the synopticscale forcing of vertical motion. The lower-stratospheric air has been replaced with air from the boundary layer, which has rapidly ascended through the full depth of the troposphere. A similar, but even more dramatic, diabatic warming of the tropopause due to latent heat release during the 1993 Superstorm is described by Bosart et al. (1996).

\section{5) The EFFECT Of DeEP CONVECTION ON THE UPPER-LEVEL TROUGH}

In Fig. 9, we see that the diabatic processes were responsible for the rapid generation of an anticyclonic PV anomaly in the upper troposphere and, equivalently, a warm potential temperature anomaly on the tropopause. Acting in tandem with the strong, digging jet streak, these processes combined to help generate the closed $250-\mathrm{hPa}$ low center at $06 / 00$ flanked by strong upstream and downstream ridges.

At 04/12, the tropopause potential temperature gradient was weak over the Great Lakes region. By 05/00, a strong temperature gradient had formed there as a result of the diabatic heating. As discussed earlier, such a gradient implies a jet streak, and indeed winds in excess of $36 \mathrm{~m} \mathrm{~s}^{-1}(70 \mathrm{kt})$ have developed there (Fig. 7). This sequence of events is typical of developing cyclones: the development of an anticyclonically curved jet downstream of the upper-level trough is coincident with the diabatic destruction of PV and the generation of a strong potential temperature gradient along the tropopause (e.g., Reed et al. 1993; Davis et al. 1996).

\section{Case study: December 1993}

This case study uses the vertical interpolation method to create tropopause maps from NMC global analyses. The case features an example of surface cyclogenesis resulting

\section{$881105 / 000072734$ SSM}

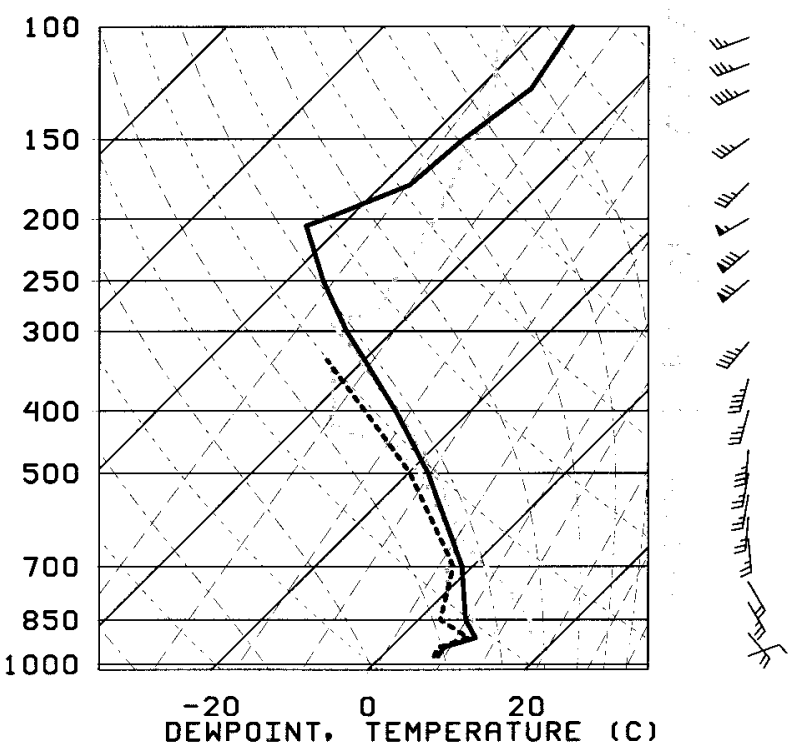

FIG. 11. As in Fig. 10 except for UMN (Monett, MO) (gray) at 1200 UTC 4 November 1988 and for SSM (Sault Ste. Marie, MI) (black) at 0000 UTC 5 November.

from the interaction of a preexisting upper-tropospheric mobile trough with a lower-tropospheric baroclinic zone. In synoptic parlance, this might be referred to as type " $\mathrm{B}$ " cyclogenesis (Petterssen and Smebye 1971).

\section{a. Conventional analyses}

The basic lower-tropospheric development can be seen in the evolution of the mean sea level pressure and the 1000-850-hPa layer averaged potential temperature (we will refer to this as the 925 -hPa $\theta$ ) (Fig. 12). At 0000 UTC 30 December 1993 (30/00) (Fig. 12a) the nascent cyclone, a surface frontal wave, was off the Maryland coast with a minimum pressure of $1003 \mathrm{hPa}^{8}$ This cyclone was situated along a nearly stationary surface front along which a series of weak cyclones had tracked from the Gulf of Mexico and offshore of the mid-Atlantic coast during the preceding $36 \mathrm{~h}$. The region in which this particular cyclone developed had been experiencing surface pressure falls of as much as $12 \mathrm{hPa}$ in the 12-h period ending 30/00. A small amplitude thermal ridge is collocated with the surface frontal wave.

By 30/12 (Fig. 12b) the surface cyclone had deepened to $977 \mathrm{hPa}$ - placing it well within the "explosive cyclogenesis" threshold established by Sanders and Gyak-

\footnotetext{
${ }^{8}$ The surface charts presented here are from the NMC global analysis at $2.5^{\circ} \times 2.5^{\circ}$ resolution. Because of this relatively coarse resolution, surface and ship observations were subjectively analyzed to determine the true intensity of the offshore cyclone.
} 

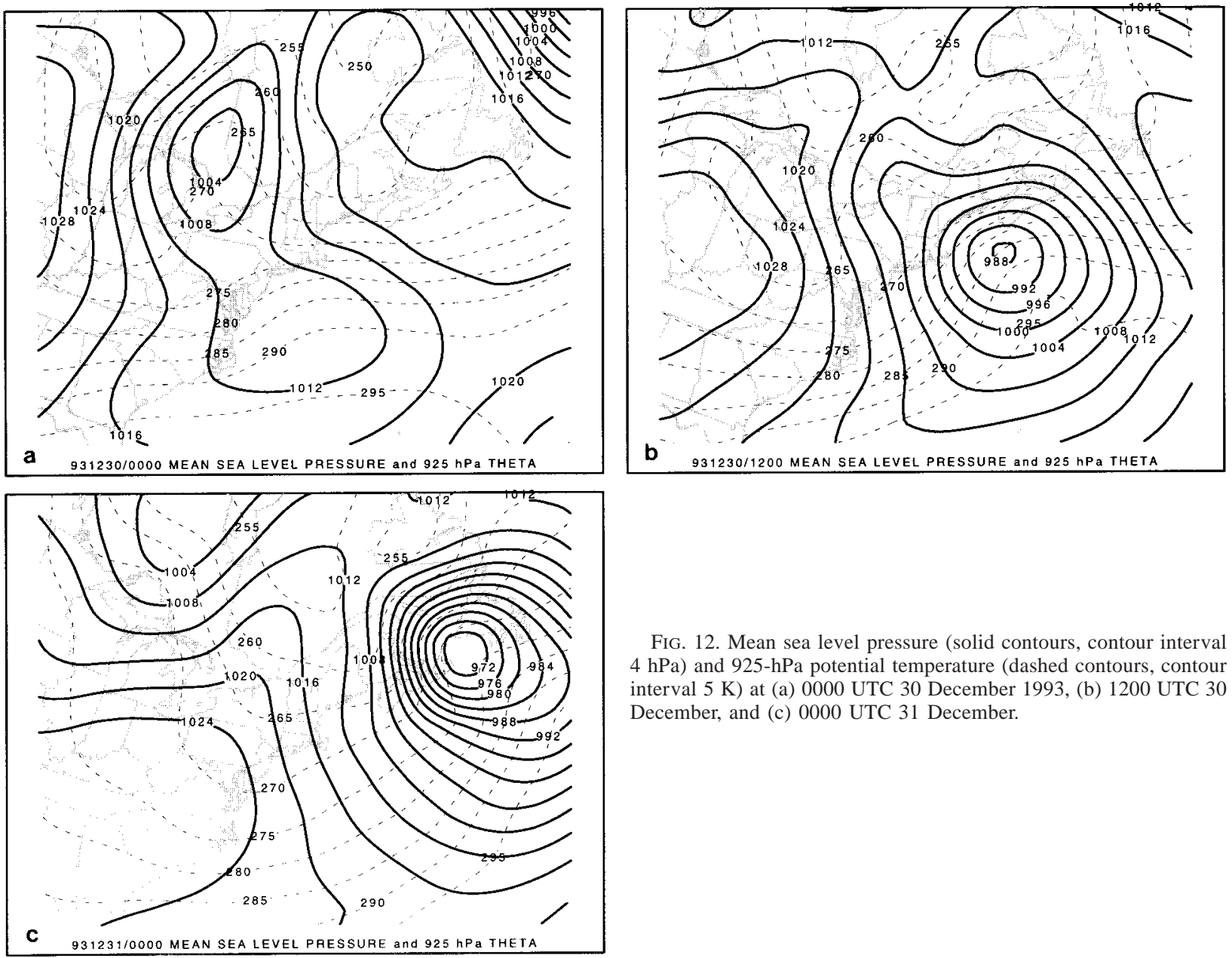

FIG. 12. Mean sea level pressure (solid contours, contour interval $4 \mathrm{hPa}$ ) and $925-\mathrm{hPa}$ potential temperature (dashed contours, contour interval $5 \mathrm{~K}$ ) at (a) 0000 UTC 30 December 1993, (b) 1200 UTC 30 December, and (c) 0000 UTC 31 December.

um (1980). The thermal ridge associated with this surface cyclone had undergone considerable amplification and had also propagated to the northeast. During the 12-h period ending at 30/12, many stations to the north and northwest of the cyclone track reported moderate to heavy snowfall rates for several hours.

The "bomb" continued to deepen as it headed northeast passing southeast of the Canadian Maritimes during the succeeding $12 \mathrm{~h}$. By 31/00 (Fig. 12c) the cyclone had deepened to $962 \mathrm{hPa}$. From 30/12 to 31/00 several stations in Nova Scotia and Newfoundland reported moderate to heavy snowfall with surface winds in excess of $17 \mathrm{~m} \mathrm{~s}^{-1}$.

The evolution of the 500-hPa geopotential height and absolute vorticity fields are shown in Fig 13. At 30/00 (Fig. 13a), a shortwave was evident over northwestern Ohio. This upper trough had originated in north-central Canada several days earlier and had been propagating along the periphery of a large cyclonic vortex centered over eastern Canada (not shown). Absolute vorticity analyses indicated a vorticity maximum (vort max) 23 $\times 10^{-5} \mathrm{~s}^{-1}$ located at the base of the $500-\mathrm{hPa}$ trough over northwestern Ohio.

Twelve hours later, at 30/12 (Fig. 13b) the trough had propagated eastward and was now situated in eastern Pennsylvania. While the intensity of the vorticity had not changed appreciably, the structure of the vorticity maximum, which had earlier been nearly symmetric about the trough axis, now displayed a secondary maximum $\left(23 \times 10^{-5} \mathrm{~s}^{-1}\right)$ to the east of Cape Cod.

By 31/00 (Fig. 13c) the shortwave had moved eastnortheast, to a position in the Canadian Maritimes. The upper trough appeared to have intensified as the height field featured a closed height contour with a minimum height of 499 dam. To the southeast of the height minimum was a vort max-now at $31 \times 10^{-5} \mathrm{~s}^{-1}$. This vort max was nearly collocated with the position of the surface cyclone. A second relative maximum in the absolute vorticity is situated to the south of the height minimum. This appears to be the same vort max discussed earlier that was located over Ohio at 30/00 and then over eastern Pennsylvania at 30/12. 

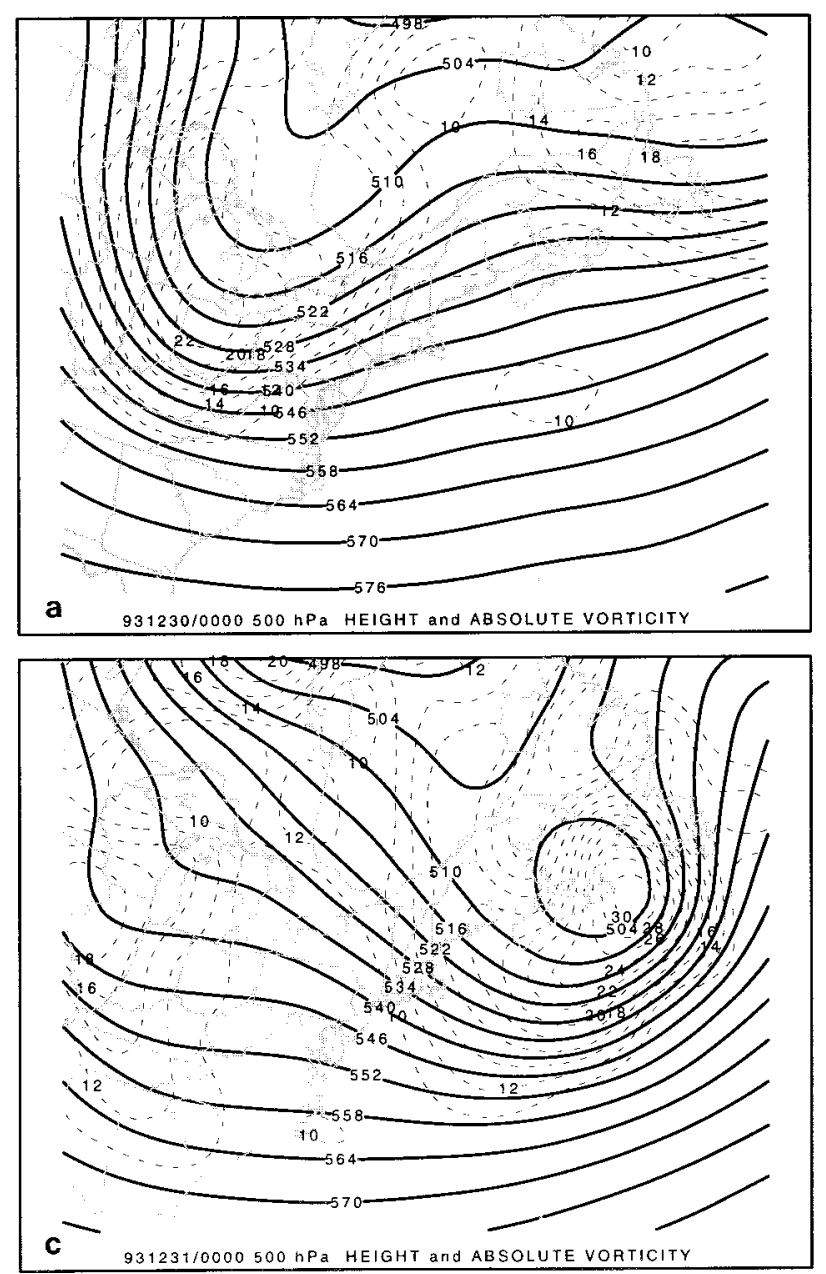

\section{b. Tropopause and lower-tropospheric $P V$ and $\theta$ distributions}

\section{1) Discussion of the eVolution of tropopause AND SURFACE $\theta$}

Tropopause potential temperature analyses at 30/00 (Fig. 14a) indicated a trough was located over northern Ohio and to its south a strong zonal jet extended from the Tennessee Valley into the central Atlantic. Winds at the tropopause suggest that the potential temperature anomaly would propagate to the east with little change in intensity (as there is no evidence of southward advection of lower potential temperature air into the base of the upper trough). The wind field also suggests that confluent frontogenesis is occurring along the western and southern periphery of the upper trough.

In the lower troposphere, to the southeast of the upper trough, the isentrope analysis (Fig. 15a) indicated a rather broad baroclinic zone extending from the southeastern United States to the south of the Canadian Maritimes. Along this baroclinic zone, a thermal ridge was located east of the Maryland coast. North of this bar-

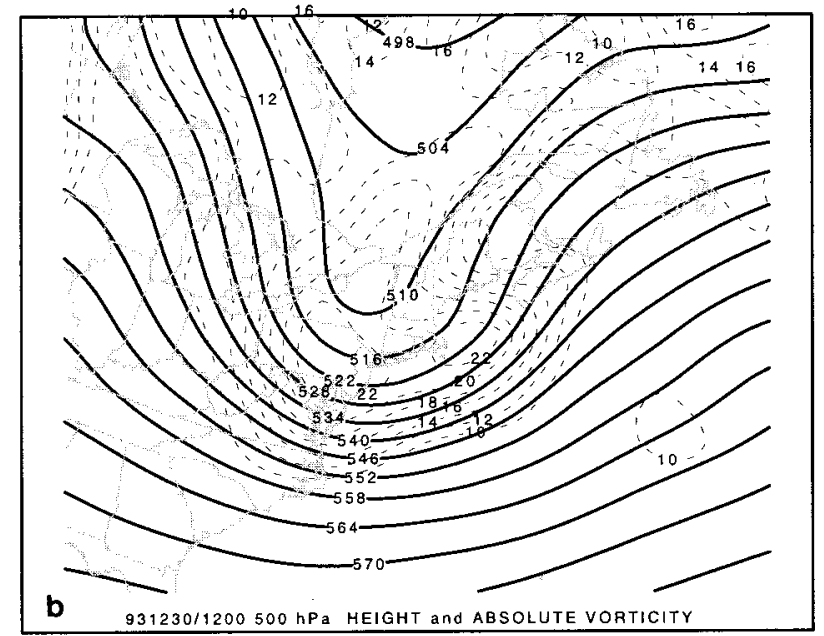

FIG. 13. The 500-hPa geopotential height (solid contours, contour interval 6 dam) and absolute vorticity (dashed contours, contour interval $2 \times 10^{-5} \mathrm{~s}^{-1}$ above $10 \times 10^{-5} \mathrm{~s}^{-1}$ ) at (a) 0000 UTC $30 \mathrm{De}-$ cember 1993, (b) 1200 UTC 30 December, and (c) 0000 UTC 31 December.

oclinic zone, the lower-tropospheric PV is generally large - a manifestation of the high stability in the cold air north of the front. The wind at $925 \mathrm{hPa}$ indicates that the thermal ridge should propagate east-northeastward (there is warm advection to the east of the ridge and cold advection to its west). The fact that there are southerly winds in phase with the $\theta$ ridge implies that the lower thermal anomaly should also amplify.

Any experienced forecaster would be able to predict rapid offshore cyclogenesis by looking at the conventional maps for 30/00. The tropopause and low-level $\theta /$ PV maps indicate in addition that while the low-level fields are nearly undisturbed, the tropopause $\theta$ gradient is initially of high amplitude and cannot intensify further through conservative processes. Therefore, rapid cyclogenesis is likely at the ground, with little or no intensification aloft. Also, the presence of a subtropical gradient $(\theta=325 \mathrm{~K}-345 \mathrm{~K})$ just south of the trough implies that the trough will be subject to cyclonic shear and should consequently develop into a classical Norwegian warm frontal occlusion (Shapiro and Grell 1994).

By 30/12 (Fig. 14b) the upper-tropospheric wave had 

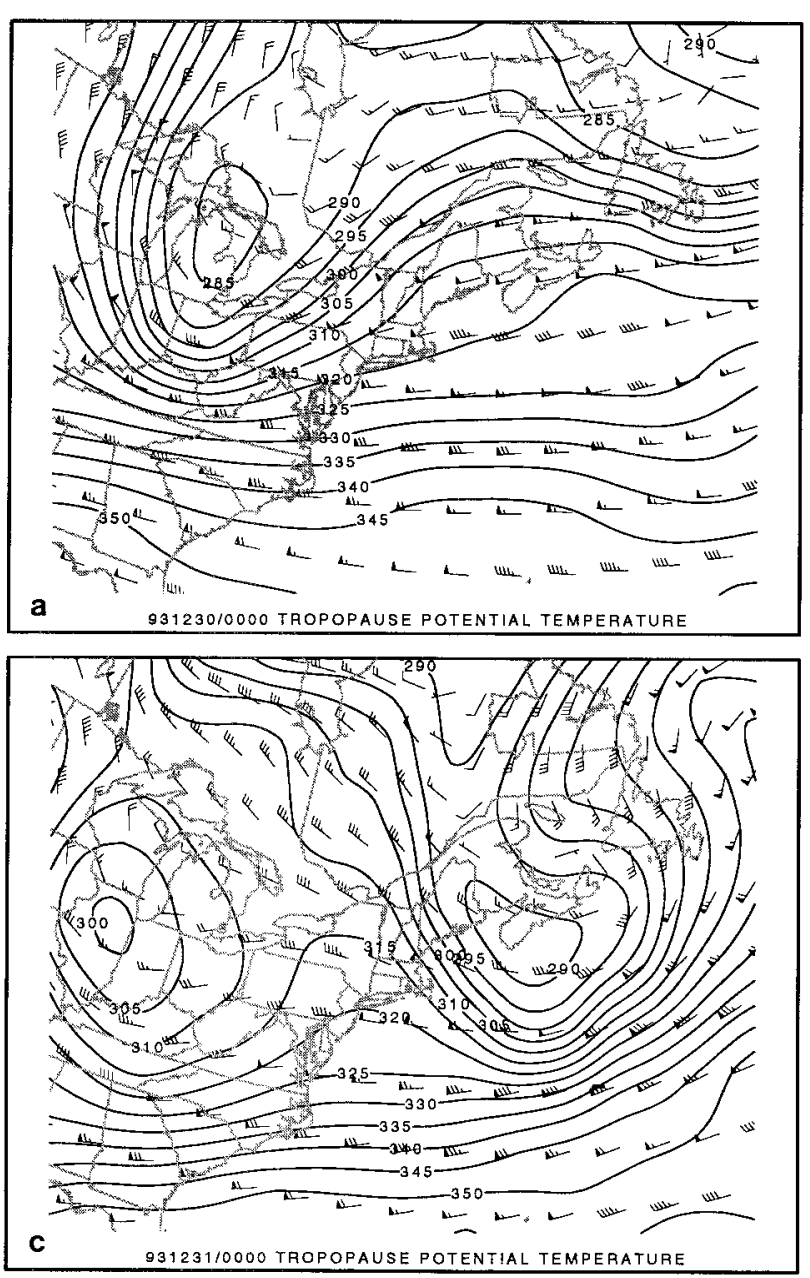

propagated eastward with the minimum tropopause $\theta$ now located over western Pennsylvania. The upper trough amplitude, as measured by the minimum potential temperature at the trough center, had not changed in the preceding $12 \mathrm{~h}$. Upper-tropospheric frontogenesis along the periphery of the upper trough had in fact occurred as evidenced by the strong thermal gradient along the base and to the west of the trough. The lowertropospheric thermal wave (Fig. 15b) had amplified considerably while propagating to the northeast. Further strengthening and a more rapid eastward propagation of the lower-tropospheric thermal anomaly are suggested by the pattern of winds shown. There was a slight increase in lower-tropospheric PV in the vicinity of the thermal ridge axis, perhaps due to the diabatic redistribution of PV associated with the precipitation observed to the northwest of the developing surface cyclone.

Both the upper trough and the thermal wave propagated east-northeastward during the 12-h period ending 31/00 (Figs. 15c and 16c, respectively). The tropopause $\theta$ analysis suggests a nonadvective tendency in $\theta$ at the trough axis as the minimum $\theta$ in the trough has increased by about $5 \mathrm{~K}$. This nonconservation of $\theta$ is likely due

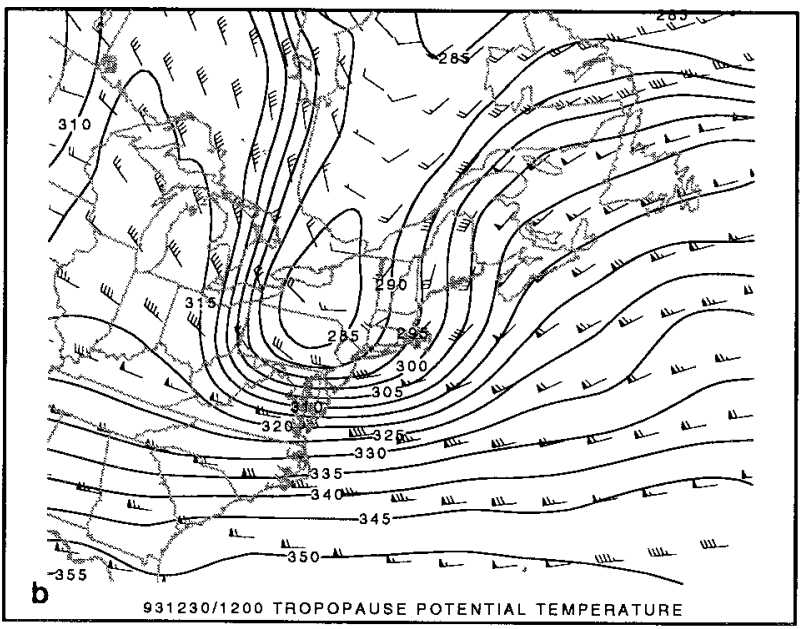

FIG. 14. Tropopause potential temperature (solid contours, contour interval $5 \mathrm{~K}$ ) and wind (short barb $=5 \mathrm{~m} \mathrm{~s}^{-1}$; long barb $=10 \mathrm{~m}$ $\mathrm{s}^{-1}$; pennant $=50 \mathrm{~m} \mathrm{~s}^{-1}$ ) at (a) 0000 UTC 30 December 1993, (b) 1200 UTC 30 December, and (c) 0000 UTC 31 December.

to analysis error as there is no evidence for diabatic processes occurring along the trough axis. On the other hand, true nonconservation appeared to take place farther east. Despite neutral to cold (potential) temperature advection downstream of the upper trough at the tropopause, potential temperatures northeast of Newfoundland and Labrador remained constant or increased. During this time, the lower-tropospheric PV had undergone a rapid increase to the north and east of the thermal ridge (and surface cyclone). These two observations, taken together, indicate a nonconservation of PV associated with diabatic processes. In this case the diabatic process is likely latent heat release in the precipitation shield north and northwest of the surface cyclone. That the region of "warming" at the tropopause is downstream of the region in the lower troposphere that experienced an increase in PV is not surprising-air parcels passing above the region of maximum heating (and thus losing their PV) are moving more rapidly northeast than those air parcels gaining PV in the lower troposphere. A consequence of this relative motion is a horizontal separation of the regions of dynamically altered PV at the tropopause and in the lower troposphere. 

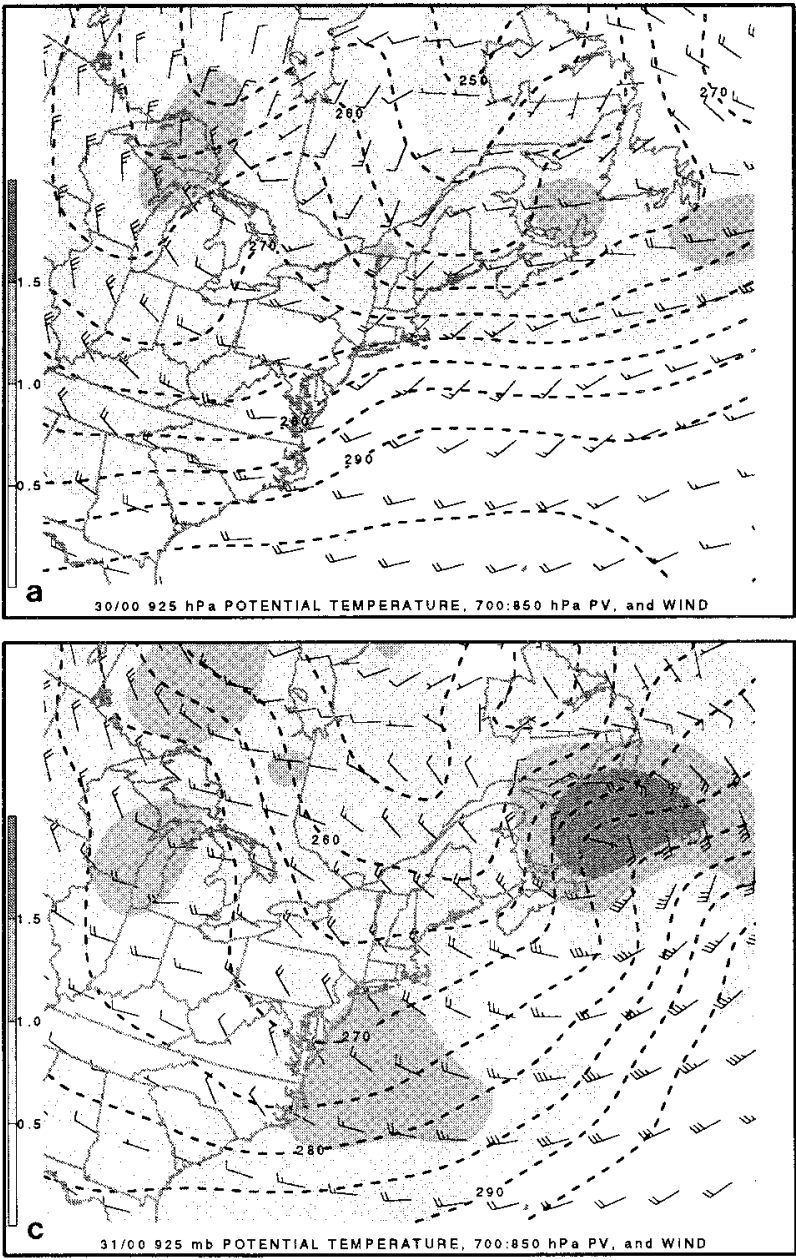

\section{2) INFERENCES MADE BASED ON THE EVOLUTION OF THE THERMAL FIELDS}

While the systematic increase in the $500-\mathrm{hPa}$ vorticity and the 500-hPa geopotential height falls may be interpreted as an amplification of the upper trough, the tropopause analyses showed no appreciable change in the tropopause PV anomaly. The increase in $500-\mathrm{hPa}$ vorticity to the east and southeast of the height minimum is in fact due to the amplification of the surface thermal wave and lower-tropospheric PV and their combined circulations at $500 \mathrm{hPa}$.

In addition to diagnosing the evolution of surface and tropopause $\theta$ distributions separately, one may qualitatively diagnose the influence tropopause (or near surface) potential temperature anomalies may have on nearsurface (or tropopause) $\theta$ distributions. To do this, one must first define the anomaly. Given a single map (time), anomalies may be defined as deviations from a spatial average. Consider the tropopause map at 30/12 (Fig. 16a). At this time the locations of the subjectively identified cyclonic (anticyclonic) tropopause anomalies are denoted with C's (A's). Note that the location of the

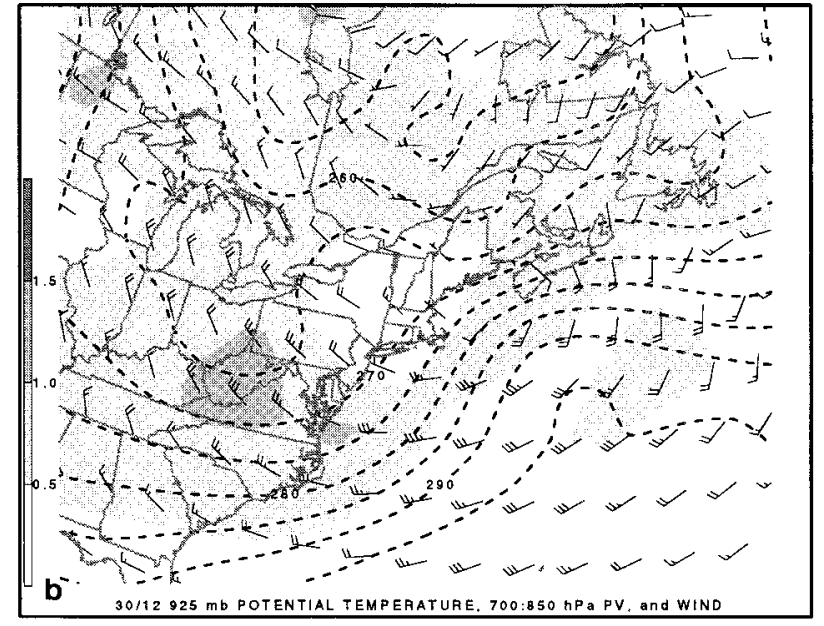

FIG. 15. The 925-hPa potential temperature (dashed, interval $5 \mathrm{~K}$ ), wind (as in Fig. 14), and 850-700-hPa Ertel PV (shaded, see figure for scale) at (a) 0000 UTC 30 December 1993, (b) 1200 UTC 30 December, and (c) 0000 UTC 31 December. tropopause anomalies do not necessarily correspond to extrema in the thermal field. As discussed in section $2 \mathrm{a}$, features in the wind field correspond closely to local extrema in the curvature of the PV (or $\theta$ ) contours. Anomalies in the $925-\mathrm{hPa} \theta$ are shown in Fig. 16b. As discussed in section 1 , these thermal anomalies have circulations that can extend through some depth of the troposphere with the depth of influence proportional to the horizontal length scale of the anomaly and inversely proportional to the basic-state stratification.

Provided that the thermal anomalies at the tropopause and near the surface have a sufficiently large depth of influence, one might infer that the effect of the tropopause $\theta$ anomalies on the lower thermal distribution (Fig. 16c) is to amplify the thermal ridge as the maximum winds associated with the tropopause anomalies are in phase with the thermal ridge. Likewise, the effect of the lower thermal ridge on the tropopause $\theta$ distribution (Fig. 16d) is to advect the cutoff tropopause thermal anomaly to the southeast. This anomaly cannot be amplified due to advection because it is a cutoff.

To quantify these ideas, an inversion of the PV anom- 

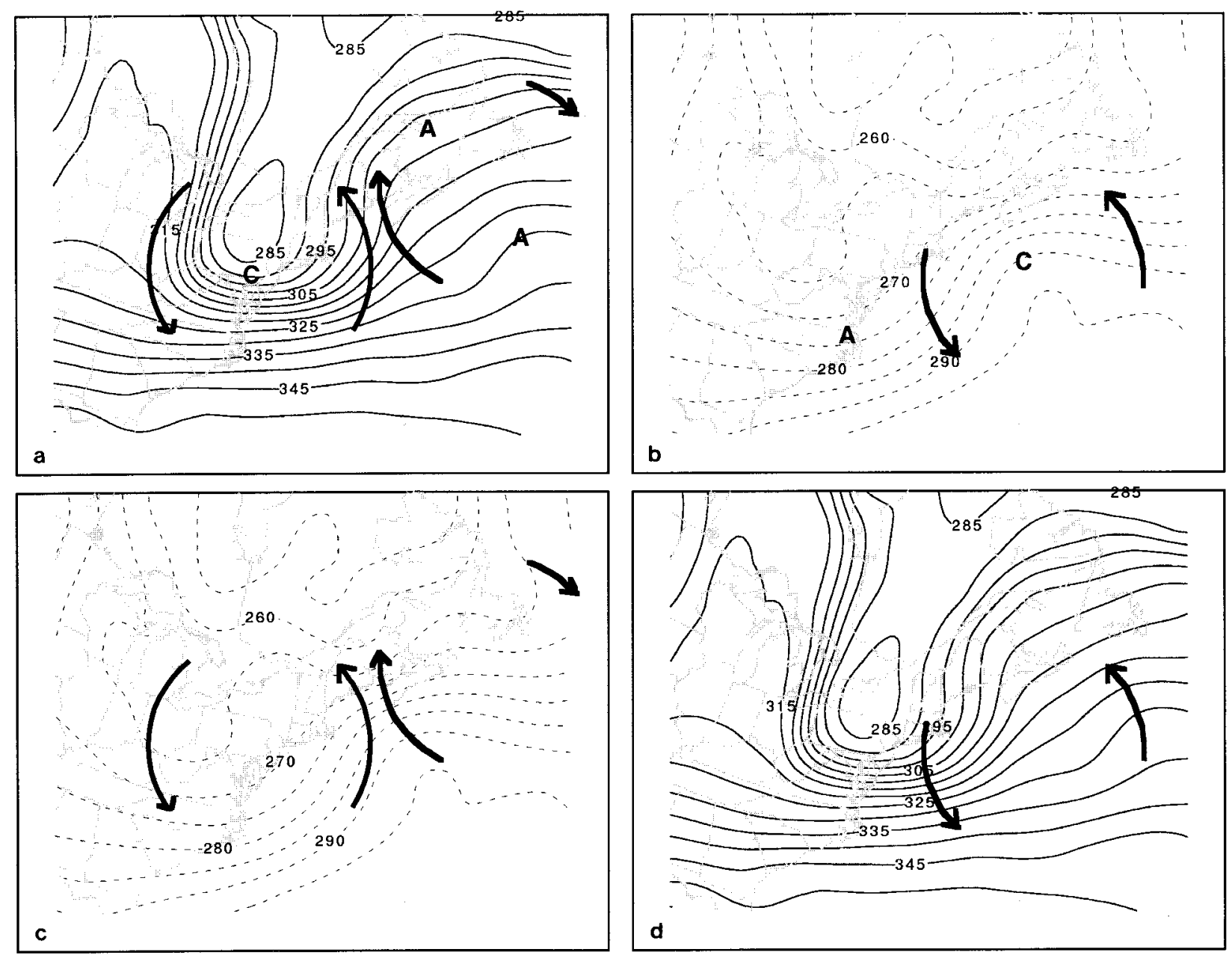

FIG. 16. For 1200 UTC 30 December 1993 (a) tropopause potential temperature (solid contour, contour interval 5 K) and arrows denoting direction of wind flow associated with subjectively identified tropopause potential temperature anomalies. Labels $\mathrm{C}$ and $\mathrm{A}$ denote location of subjectively identified cyclonic and anticyclonic tropopause potential temperature anomalies. (b) The 925-hPa potential temperature (dashed contour, contour interval $5 \mathrm{~K}$ ) and arrows denoting direction of $925-\mathrm{hPa}$ wind flow associated with subjectively identified 925 -hPa potential temperature anomalies. Labels $\mathrm{C}$ and $\mathrm{A}$ denote location of subjectively identified cyclonic and anticyclonic 925 -hPa potential temperature anomalies. (c) The 925-hPa potential temperature (dashed contour, contour interval $5 \mathrm{~K}$ ) and arrows denoting direction of 925-hPa wind flow associated with subjectively identified tropopause potential temperature anomalies identified in (a). (d) Tropopause potential temperature (solid contour, interval $5 \mathrm{~K}$ ) and arrows denoting direction of wind flow associated with subjectively identified 925 -hPa potential temperature anomalies identified in (b).

alies was performed using the piecewise PV inversion technique detailed in Davis and Emanuel (1991). Anomalies were defined as deviations from a 5-day mean centered on 1200 UTC 29 December. ${ }^{9}$ The tropospheric $\mathrm{PV}$ was divided in half-the upper-tropospheric PV was composed of all PV above and including $500 \mathrm{hPa}$, whereas the lower-tropospheric PV was composed of $\mathrm{PV}$ below $500 \mathrm{hPa}$ including the $925-\mathrm{hPa} \theta$, which served as a lower boundary condition. The results of

${ }^{9}$ To the extent that the upper trough and lower-tropospheric thermal ridge propagated at a constant speed, one may anticipate that the anomalies defined in this way are approximately the same as those identified qualitatively. the inversion for 30/12 are shown in Fig. 17. The balanced wind fields associated with the PV anomalies are overlaid on the tropopause and lower-tropospheric $\theta$ fields. The results support the inference that the tropopause anomalies' circulations served to amplify the near-surface thermal ridge as the winds associated with the tropopause anomalies are in fact in phase with the 925-hPa thermal ridge. Comparing Figs. 17a,b with Figs. $17 \mathrm{c}$,d, one can also see that the respective circulations diminish in amplitude with height. While the sense and location of the lower-tropospheric anomalies' circulations were correctly inferred, the magnitudes of the anomalies' wind fields at the tropopause were insufficient to advect the upper trough to the southeast.

Traditionally, surface cyclogenesis is diagnosed by 

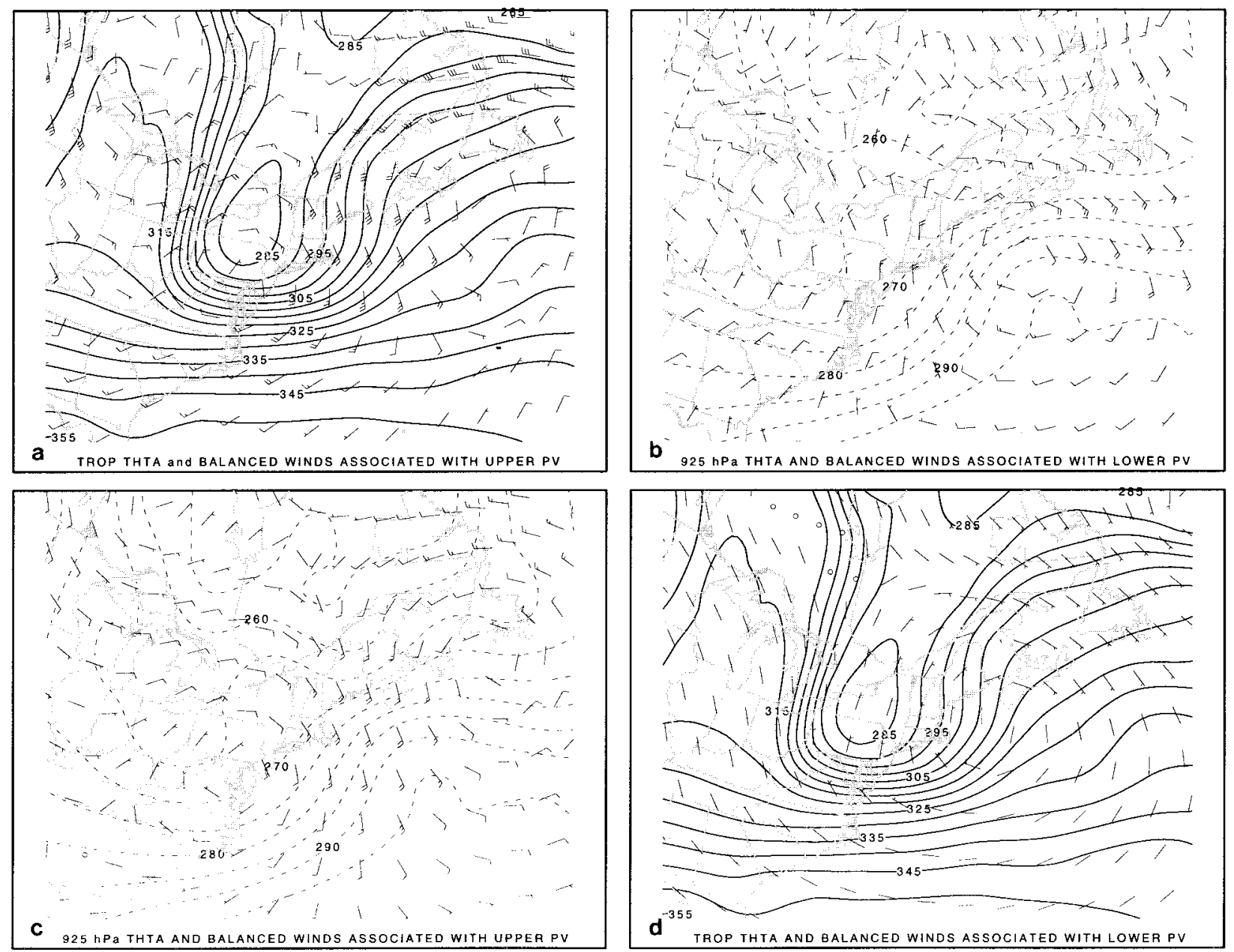

FIG. 17. For 0000 UTC 30 December 1993 (a) tropopause potential temperature (solid contour, interval 5 K) and balanced winds (short barb $=5 \mathrm{~m} \mathrm{~s}^{-1}$ and long barb $=10 \mathrm{~m} \mathrm{~s}^{-1}$ ) interpolated to the tropopause associated with PV anomalies at and above 500 hPa. (b) The 925$\mathrm{hPa}$ potential temperature (dashed, interval $5 \mathrm{~K}$ ) and 925-hPa balanced winds associated with PV anomalies below 500 hPa. (c) The 925$\mathrm{hPa}$ potential temperature (dashed, interval $5 \mathrm{~K}$ ) and $925-\mathrm{hPa}$ balanced winds associated with $\mathrm{PV}$ anomalies at and above $500 \mathrm{hPa}$, and $(\mathrm{d}$ ) tropopause potential temperature (solid contour, interval $5 \mathrm{~K}$ ) and balanced winds interpolated to the tropopause associated with PV anomalies below $500 \mathrm{hPa}$.

identifying regions of lower-tropospheric ascent (usually diagnosed using the $\mathrm{QG} \omega$ equation) overlying a minimum in sea level pressure (or a lower-tropospheric vorticity maximum). Lower-tropospheric ascent is associated with lower-tropospheric convergence and concomitant "spinup" of low-level vorticity through vortex tube stretching - that is, surface cyclogenesis. Figure 18 shows the 700-hPa geostrophic "forcing term" for vertical motion in the $\mathbf{Q}$-vector form of the QG $\omega$ equation (Hoskins and Pedder 1980). As this pattern is generally typical of the lower troposphere, the $\mathbf{Q}$-vector convergence to the southeast of Nova Scotia suggests that ascent is occurring in that region. Because this region of ascent is partially in phase and ahead of the surface cyclone, deepening and a northeast propagation would be diagnosed.

While knowledge of the secondary circulation is used to diagnose cyclogenesis by traditional means, for di- agnosis of cyclogenesis using PV thinking, this is not necessary. The development is diagnosed using the "primary," balanced flow: by identifying regions of positive horizontal advection of near-surface $\theta$, by the balanced flow, amplification of the thermal anomaly may be diagnosed. ${ }^{10}$ This amplification implies an increase in the cyclonic circulation associated with the lower thermal anomaly, which in turn implies (through invertibility) a deepening of the surface cyclone. Explicit knowledge of the secondary circulation is not required, but is implicit: local tendencies in distributions

\footnotetext{
${ }^{10}$ The net northeastward motion of the surface cyclone is caused, according to PV thinking, by the eastward self-propagation of the thermal anomaly (Fig. 17b) and the northward advection and amplification of the thermal anomaly by the winds associated with the upper-level PV anomaly.
} 


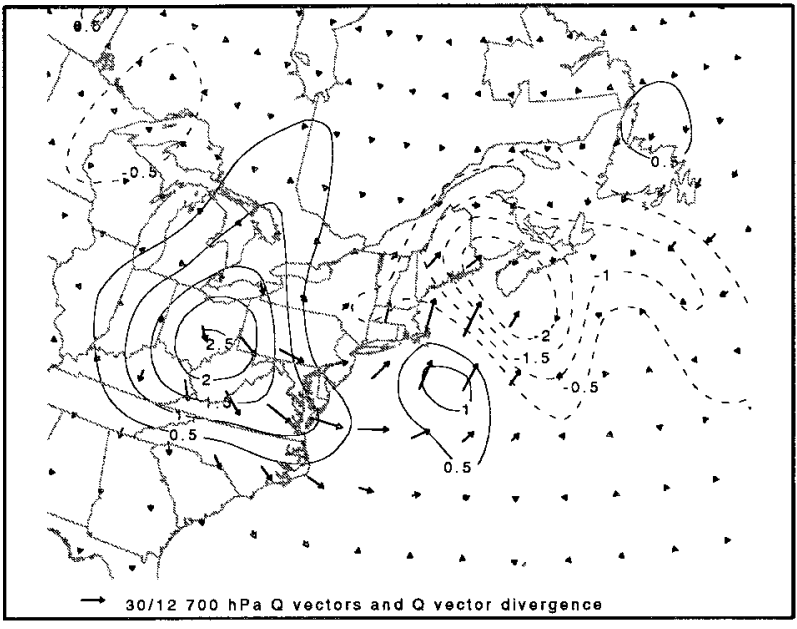

FIG. 18. For 1200 UTC 30 December 1993 700-hPa quasigeostrophic $\mathbf{Q}$ vectors (reference vector (located to left of figure title) length $10 \times 10^{-10} \mathrm{~K} \mathrm{~s}^{-1}$ ) and $\mathbf{Q}$-vector convergence (contour interval $0.4 \times 10^{-15} \mathrm{~K} \mathrm{~m}^{-1} \mathrm{~s}^{-1}$ ).

of surface $\theta$, or more generally tropospheric PV, imply a nonzero vertical motion (HMR).

\section{Summary}

Observations suggesting that the tropospheric synoptic-scale flow is quasi-balanced imply that knowledge of the distribution of PV and its time tendency are sufficient to describe the large-scale tropospheric flow and its evolution. Based on the typical distribution of PV in the troposphere and lower stratosphere, we advocate an alternate approach to isentropic analyses of PV for depicting the salient features of the upper-tropospheric PV distribution-identifying the dynamic tropopause as a surface of constant Ertel PV (an isertelic surface) and analyzing potential temperature along that PV surface. This approach retains the dynamical advantages inherent in viewing the evolution of a conserved variable along a material surface (e.g., isentropic distributions of PV), while allowing the upper-tropospheric PV distribution to be compactly represented. Tropopause analyses are complemented with analyses of lower-tropospheric PV and near-surface (equivalent) potential temperature. Together, the isertelic analyses of $\theta$ and the lower-tropospheric analyses of $\theta$ or $\theta_{e}$ form what may be considered an "Eady model representation" of tropospheric dynamics, wherein the dynamics of the troposphere are determined primarily by the evolution of potential temperature along the tropopause and just above the surface.

Various phenomena associated with midlatitude weather systems may be diagnosed using this dynamical representation of the tropospheric PV distribution: surface and upper-tropospheric cyclone development and propagation, upper-tropospheric frontogenesis and tropopause folding, and the effect of latent heating (either associated with radiational cooling or deep moist con- vection) on the balanced flow. The use of the analyses also allows for an assessment of potential (convective) instability of deep tropospheric columns.

Because the evaluation and interpretation of output from numerical weather prediction models is an important step in the diagnosis and forecasting of tropospheric weather systems, this representation may have its greatest utility in the forecast office. As forecasters are now confronted with a wide suite of models and ensemble model output, the evaluation of various model output products has become a challenge. Distinguishing the dynamically significant differences between various models and the differences between different initializations of the same model is important. In an operational setting, the representation of model output in as compact a manner as possible is essential. The compactness of tropopause maps allows the many advantages of PV thinking (identifying dynamically significant upper-level features, assessing potential for development, determining the range of possible scenarios, tracking upperlevel systems over high topography) to be applied at the forecast desk.

Acknowledgments. The authors are grateful to Drs. Kerry Emanuel, Christopher Davis, and Gary Lackmann for their enlightening discussions concerning potential vorticity and balanced flows and for their suggestions of various means for depicting tropospheric distributions of potential vorticity. This material is based upon work supported by the National Science Foundation under Grants ATM-9313785 and ATM-9553284.

\section{REFERENCES}

Ambaum, M., 1997: Isentropic formation of the tropopause. J. Atmos. Sci., 54, 555-568.

Bell, G. D., and L. F. Bosart, 1988: Appalachian cold-air damming. Mon. Wea. Rev., 116, 137-161.

- and - 1993: A case study diagnosis of the formation of an upper-level cutoff cyclonic circulation over the eastern United States. Mon. Wea. Rev., 121, 1635-1655.

Bellamy, J., 1949: Objective calculations of divergence, vertical velocity, and vorticity. Bull. Amer. Meteor. Soc., 30, 45-49.

Black, R., and R. Dole, 1993: The dynamics of large-scale cyclogenesis over the North Pacific Ocean. J. Atmos. Sci., 50, 421442.

Bleck, R., 1990: Depiction of upper/lower vortex interaction associated with extratropical cyclogenesis. Mon. Wea. Rev., 118, 573-585.

Bosart, L. F., and J. W. Nielsen, 1993: Radiosonde penetration of an undilute cumulonimbus anvil. Mon. Wea. Rev., 121, 1688-1702.

— , and G. M. Lackmann, 1995: Postlandfall tropical cyclone reintensification in a weakly baroclinic environment: A case study of Hurricane David (September 1979). Mon. Wea. Rev., 123, 3268-3291.

, G. J. Hakim, K. R. Tyle, M. A. Bedrick, W. E. Bracken, M. J. Dickinson, and D. M. Schultz, 1996: Large-scale antecedent conditions associated with the 12-14 March 1993 cyclone ("Superstorm '93") over eastern North America. Mon. Wea. Rev., 124, 1865-1891.

Bresky, W. C., and S. J. Colucci, 1996: A forecast and analyzed cyclogenesis event diagnosed with potential vorticity. Mon. Wea. Rev., 124, 2227-2244. 
Bretherton, F. P., 1966: Critical layer instability in baroclinic flows. Quart. J. Roy. Meteor. Soc., 92, 325-334.

Ceselski, B., and L. Sapp, 1975: Objective wind field analysis using line integrals. Mon. Wea. Rev., 103, 89-100.

Charney, J., 1947: The dynamics of long waves in a baroclinic westerly current. J. Meteor., 4, 135-162.

- 1955: The use of the primitive and balance equations. Tellus, 7, 22-26.

— , and M. E. Stern, 1962: On the stability of internal baroclinic jets in a rotating atmosphere. J. Atmos. Sci., 19, 159-172.

Danielsen, E., 1968: Stratospheric-tropospheric exchange based on radioactivity, ozone, and potential vorticity. J. Atmos. Sci., 25, 502-518.

—, and R. Hipskind, 1980: Stratospheric-tropospheric exchange at polar latitudes in summer. J. Geophys. Res., 85, 393-400.

Davis, C. A., 1992a: Piecewise potential vorticity inversion. J. Atmos. Sci., 49, 1397-1411.

- 1992b: A potential vorticity diagnosis of the importance of initial structure and condensational heating in observed cyclogenesis. Mon. Wea. Rev., 120, 2409-2428.

- , and K. Emanuel, 1991: Potential vorticity diagnostics of cyclogenesis. Mon. Wea. Rev., 119, 1929-1953.

- M. T. Stoelinga, and Y.-H. Kuo, 1993: The integrated effect of condensation in numerical simulations of extratropical cyclogenesis. Mon. Wea. Rev., 121, 2309-2330.

— E. D. Grell, and M. A. Shapiro, 1996: The balanced dynamical nature of a rapidly intensifying oceanic cyclone. Mon. Wea. Rev., 124, 3-26.

Defant, F., and H. Taba, 1957: The threefold structure of the atmosphere and the characteristics of the tropopause. Tellus, 9, 259274.

Eady, E., 1949: Long waves and cyclone waves. Tellus, 1, 33-42.

Eliassen, A., and E. Kleinschmidt, 1957: Cyclones and anticyclones. Dynamic Meteorology, S. Flugge, Ed., Vol. 48, Springer-Verlag, $112-154$

Emanuel, K., 1985: Frontal circulations in the presence of small moist symmetric instability. J. Atmos. Sci., 42, 1062-1071.

Fritsch, J. M., and R. A. Maddox, 1981: Convectively driven mesoscale weather systems aloft. Part I: Observations. J. Appl. Meteor., 20, 9-19.

Gent, P., and J. McWilliams, 1983: Consistent balanced models in bounded and periodic domains. Dyn. Atmos. Oceans, 7, 67-93.

Hakim, G., L. Bosart, and D. Keyser, 1995: The Ohio Valley wavemerger cyclogenesis event of 25-26 January 1978. Part I: Multiscale case study. Mon. Wea. Rev., 123, 2663-2692.

$\_,-$, and — 1996: The Ohio Valley wave-merger cyclogenesis event of 25-26 January 1978. Part II: Diagnosis using quasigeostrophic potential vorticity inversion. Mon. Wea. Rev., 124, 2176-2205.

Held, I., R. Pierrehumbert, S. Garner, and K. Swanson, 1995: Surface quasi-geostrophic dynamics. J. Fluid Mech., 282, 1-20.

Hoerling, M., K. Schaak, and A. Lenzen, 1991: Global objective tropopause analysis. Mon. Wea. Rev., 119, 1816-1831.

Holopainen, E., and J. Kaurola, 1991: Decomposing the atmospheric flow using potential vorticity framework. J. Atmos. Sci., 48, $2614-2625$

Hoskins, B., and M. Pedder, 1980: The diagnosis of middle latitude synoptic development. Quart. J. Roy. Meteor. Soc., 106, 707 719

, and P. Berrisford, 1988: A potential vorticity perspective of the storm of 15-16 October ' 87 . Weather, 43, 122-129.

- M. McIntyre, and A. Roberston, 1985: On the use and significance of isentropic potential vorticity maps. Quart. J. Roy. Meteor. Soc., 111, 877-946.

Joly, A., and A. Thorpe, 1990: Frontal instability generated by tropospheric potential vorticity anomalies. Quart. J. Roy. Meteor. Soc., 116, 525-560.

Juckes, M., 1994: Quasigeostrophic dynamics of the tropopause. $J$. Atmos. Sci., 51, 2756-2768.

Keyser, D., and M. A. Shapiro, 1986: A review of the structure and dynamics of upper-level frontal zones. Mon. Wea. Rev., 114, 452-499.

Koch, S. E., M. desJardins, and P. J. Kocin, 1983: An interactive Barnes objective map analysis scheme for use with satellite and conventional data. J. Climate Appl. Meteor., 22, 1487-1503.

Lackmann, G. M., D. Keyser, and L. F. Bosart, 1997: A characteristic life cycle of upper-tropospheric cyclogenetic precursors during the Experiment on Rapidly Intensifying Cyclones over the Atlantic (ERICA). Mon. Wea. Rev., 125, 2729-2758.

Lamarque, J.-F., and P. Hess, 1994: Cross-tropopause mass exchange and potential vorticity budget in a simulated tropopause folding. J. Atmos. Sci., 51, 2246-2269.

Morgan, M., 1994: An observationally and dynamically determined basic state of the study of synoptic scale waves. Ph.D. thesis, Massachusetts Institute of Technology, 123 pp. [Available from Michael C. Morgan, University of Wisconsin-Madison, 1225 W. Dayton Street, Madison, WI 53706.]

— , P. Neilley, and R. Dole, 1991: Scale interactions and diabatic processes during the development of an Atlantic blocking event. Preprints, First Int. Symp. on Winter Storms, New Orleans, LA, Amer. Meteor. Soc., 62-65.

National Climatic Data Center, 1988: Storm Data. Vol. 30, No. 10 , 76 pp. [Available from the National Climatic Data Center, 151 Patton Ave., Asheville, NC 28801-5001.]

Nielsen, J. W., 1988: Direct analysis of Ertel potential vorticity. Synoptic Meteorology: Notes from an NCAR Summer Colloquium, F. Carr, Ed., National Center for Atmospheric Research, 38-47.

— C. A. Davis, and D. Keyser, 1991: Upper-level frontogenesis made easy? Preprints, First Int. Symp. on Winter Storms, New Orleans, LA, Amer. Meteor. Soc., 82-87.

Nielsen-Gammon, J., 1995: Dynamical conceptual models of upperlevel mobile trough formation: Comparison and application. Tellus, 47A, 705-721.

— development of an upper-tropospheric mobile trough. J. Atmos. Sci., 53, 3120-3142.

Neiman, P., M. Shapiro, E. Donall, and C. Kreitzberg, 1990: Diabatic modification of an extratropical cyclone warm sector by cold underlying water. Mon. Wea. Rev., 118, 1576-1590.

Palmén, E., and C. W. Newton, 1969: Atmospheric Circulation Systems: Their Structure and Physical Interpretation. Academic Press, 603 pp.

Petterssen, S., and S. Smebye, 1971: On the development of extratropical cyclones. Quart. J. Roy. Meteor. Soc., 97, 457-482.

Platzman, G., 1949: The motion of barotropic disturbances in the upper troposphere. Tellus, 1, 53-64.

Reed, R. J., G. A. Grell, and Y.-H. Kuo, 1993: The ERICA IOP5 Storm. Part II: Sensitivity tests and further diagnosis based on model output. Mon. Wea. Rev., 121, 1595-1612.

Robinson, W., 1988: Analysis of LIMS data by potential vorticity inversion. J. Atmos. Sci., 45, 2319-2342.

_ 1989: On the structure of potential vorticity in baroclinic instability. Tellus, 41A, 275-284.

Rotunno, R., W. Skamarock, and C. Snyder, 1994: An analysis of frontogenesis in numerical simulations of baroclinic waves. $J$. Atmos. Sci., 51, 3373-3398.

Sanders, F., and J. Gyakum, 1980: Synoptic-dynamic climatology of the "bomb." Mon. Wea. Rev., 108, 1589-1606.

Schaefer, J., and C. Doswell III, 1979: On the interpolation of a vector field. Mon. Wea. Rev., 107, 458-476.

Shapiro, M. A., 1980: Turbulent mixing within tropopause folds as a mechanism for the exchange of chemical constituents between the stratosphere and troposphere. J. Atmos. Sci., 37, 994-1004. , and D. Keyser, 1990: Fronts, jet streams and the tropopause. Extratropical Cyclones: The Erik Palmén Memorial Volume, C. Newton and E. O. Holopainen, Eds., Amer. Meteor. Soc., 167191.

_ and E. D. Grell, 1994: In search of synoptic/dynamic conceptualizations of the life cycles of fronts, jet streams, and the tro- 
popause. The Life Cycles of Extratropical Cyclones, Vol. I, S. Gronas and M. A. Shapiro, Eds., Aase Grafiske A/S, 163-181.

—, T. Hampel, and A. J. Krueger, 1987: The Arctic tropopause fold. Mon. Wea. Rev., 115, 444-454.

Spaete, P., D. Johnson, and T. Schaak, 1994: Stratospheric-tropospheric mass exchange during the Presidents' Day storm. Mon. Wea. Rev., 122, 424-439.

Staley, D., 1962: On the mechanism of mass and radioactivity transport from stratosphere and troposphere. J. Atmos. Sci., 19, 450467.

Sun, D.-Z., and R. Lindzen, 1994: A PV view of the zonal mean distribution of temperature and wind in the extratropical troposphere. J. Atmos. Sci., 51, 757-772.

Thorncroft, C., B. Hoskins, and M. McIntyre, 1993: Two paradigms of baroclinic-wave life cycle behavior. Quart. J. Roy. Meteor. Soc., 119, 17-55.

Thorpe, A. J., 1986: Synoptic-scale disturbances with circular symmetry. Mon. Wea. Rev., 114, 1384-1389.
— analogy: Ertel-Rossby formulation. Quart. J. Roy. Meteor. Soc., 121, 1477-1495.

Uccellini, L. W., 1990: Processes contributing to the rapid development of extratropical cyclones. Extratropical Cyclones: The Erik Palmén Memorial Volume, C. Newton and E. O. Holopainen, Eds., Amer. Meteor. Soc., 81-105.

World Meteorological Organization, 1992: International Meteorological Vocabulary. WMO, $784 \mathrm{pp}$.

Wu, C.-C., and K. A. Emanuel, 1993: Interaction of a baroclinic vortex with background shear: Application to hurricane movement. J. Atmos. Sci., 50, 62-76.

$\longrightarrow$, and _ 1995a: Potential vorticity diagnostics of hurricane movement. Part I: A case study of Hurricane Bob (1991). Mon. Wea. Rev., 123, 69-92.

$\longrightarrow$, and — 1995b: Potential vorticity diagnostics of hurricane movement. Part II: Tropical Storm Ana (1991) and Hurricane Andrew (1992). Mon. Wea. Rev., 123, 93-109. 